\title{
Measuring the Effects of Interpretive Journalism on Trust and Credibility Perceptions in the Context of Political News Coverage
}

\author{
Scott William Siker \\ West Virginia University, swsiker@mix.wvu.edu
}

Follow this and additional works at: https://researchrepository.wvu.edu/etd

Part of the Social and Behavioral Sciences Commons

\section{Recommended Citation}

Siker, Scott William, "Measuring the Effects of Interpretive Journalism on Trust and Credibility Perceptions in the Context of Political News Coverage" (2019). Graduate Theses, Dissertations, and Problem Reports. 4098.

https://researchrepository.wvu.edu/etd/4098

This Thesis is protected by copyright and/or related rights. It has been brought to you by the The Research Repository @WVU with permission from the rights-holder(s). You are free to use this Thesis in any way that is permitted by the copyright and related rights legislation that applies to your use. For other uses you must obtain permission from the rights-holder(s) directly, unless additional rights are indicated by a Creative Commons license in the record and/ or on the work itself. This Thesis has been accepted for inclusion in WVU Graduate Theses, Dissertations, and Problem Reports collection by an authorized administrator of The Research Repository @ WVU. For more information, please contact researchrepository@mail.wvu.edu. 
2019

Measuring the Effects of Interpretive Journalism on Trust and Credibility Perceptions in the Context of Political News Coverage

Scott William Siker

Follow this and additional works at: https://researchrepository.wvu.edu/etd 


\title{
Measuring the Effects of Interpretive Journalism on Trust and Credibility Perceptions in the Context of Political News Coverage
}

\author{
Scott Siker
}

Thesis submitted to the Reed College of Media at West Virginia University

In partial fulfillment of the requirement for the degree of Master of Science in Journalism

\author{
Geah Pressgrove, Ph.D., Chair \\ Julia Fraustino, Ph.D. \\ Elizabeth Oppe, Ph.D. \\ Elizabeth Cohen, Ph.D. \\ Department of Journalism
}

\section{Morgantown, West Virginia \\ 2019}

Keywords: Interpretive journalism, media distrust, message credibility, message trust, political ideology, news, framing

Copyright 2019 Scott Siker 


\section{ABSTRACT \\ Measuring the Effects of Interpretive Journalism on Trust and Credibility Perceptions in the Context of Political News Coverage}

Scott Siker

This study examines the effects of interpretive journalism on trust and credibility perceptions. Specifically, this study investigates interpretive journalism in the context of political news coverage and also examines the relationship between political ideology and the aforementioned variables. This study uses a 2 (interpretive journalism; fact-based journalism) $\mathrm{x}$ 2 (political ideology: conservative leaning; liberal leaning) between-subjects online experiment to test the proposed hypotheses. Findings illustrate the predictive value of credibility to trust within the context of political news coverage. Additionally, this study shows that individuals exhibit higher perceptions of trust and credibility towards fact-based political coverage as opposed to interpretive political coverage. Preliminary findings also indicate that conservatives exhibit lower perceptions of trust and credibility towards interpretive political news coverage than their liberal counterpart. 


\section{Table of Contents}

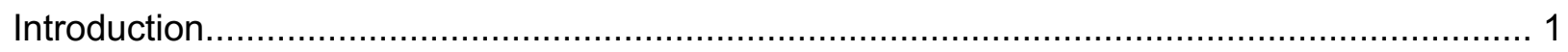

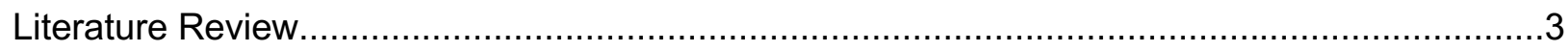

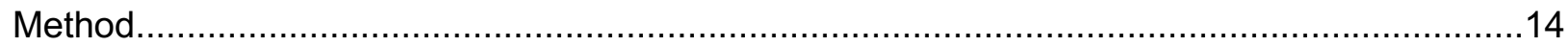

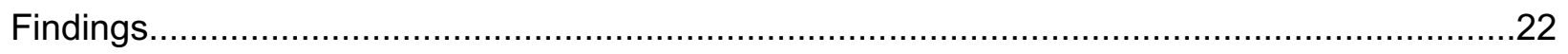

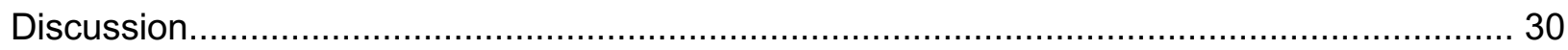

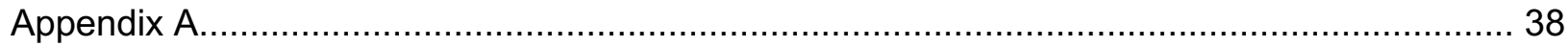

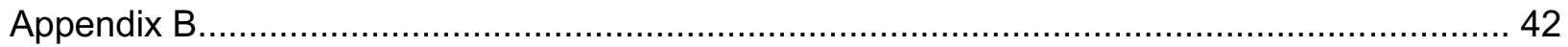

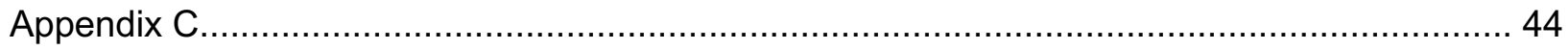

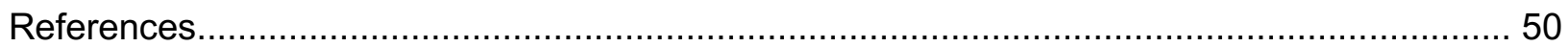


"Our liberty depends on the freedom of the press, and that cannot be limited without being lost" (Jefferson, T. 1786, January 28). -Thomas Jefferson

The freedom of the press, guaranteed by the first amendment of the U.S. Bill of Rights, is an essential institution for preserving American democracy (Curran, 2011; Fenton, 2012). Throughout the country's history, the mass media has played important roles in U.S. society by serving as a watchdog to government (Kovach \& Rosenstiel, 2001), the main provider of information to the American people (Whitten-Woodring, 2009) and a proponent of civic engagement (Zúñiga, Jung \& Valenzuela, 2012.). An example of this watchdog role is illustrated by the media's involvement in the Watergate scandal exposing the corruption within the Nixon administration (Luberda, 2014). Further, it has been said that "citizens have an obligation to become informed about public issues, to monitor the conduct of their leaders and representatives, and to express their own opinions" (Stanford University n.d., para. 7). The news media provides unfettered access to information, allowing citizens to monitor and engage on public issues in an informed manner.

Historically, the importance of media as part of a functioning democracy in the U.S. is difficult to debate. Despite its importance, there is cause for concern when examining the substantial decline in America's trust in the media in recent years. For the first time in the 19year history of the Edelman Trust Barometer, the media has become the public's least trusted institution (Global Trust Index, 2018). Overall lack of trust in the news media can be attributed to various factors including a "concern about bias, spin and hidden agendas" (Bilton, 2017, para. 3). In fact, in 2014 just 22.8 percent of the U.S. population said the press can be trusted (Hanitzsch, Van Dalen, \& Steindl 2018). The dependence of the American people on the media combined with a high level of distrust creates an interesting socio-political dichotomy. 
Many studies have been conducted in an effort to understand the potential causes for this decline in media trust. A common theme of studies conducted on media distrust is the examination of political news coverage (Hopmann, Shehata, \& Strömbäck, 2015; Jones, 2004; Patterson, 2017). Scholars have examined media distrust from various points of view central to the aims of this study. These include the effects of different types of framing (Becker, 2011; Cole, \& Greer, 2013; Hopmann et al., 2015; Shen, Ahern, \& Backer, 2014), political affiliation (Jones, 2004; Lin, Haridakis, \& Hanson, 2016; Swift, 2016), media credibility (Appelman \& Sundar, 2016; Cole \& Greer 2013; Johnson \& Kaye, 2009; Stroud \& Lee, 2013) and interpretive journalism included within reporting (Barthel \& Gottfried, 2016). Although scholars have long discussed distrust in the media, there has been less emphasis on the factors that lead to trust in political news coverage. This study seeks to fill this gap in the literature.

Within the context of understanding when Americans trust political news coverage, two important variables to consider are interpretive journalism and political ideology. Interpretive journalism can be characterized as going beyond verifiable facts and providing journalistic explanation (Salgado \& Strömbäck, 2011). While journalistic explanation can take many forms, a characterization could include a journalist drawing conclusions within their reporting as opposed to just relaying facts from which the reader can draw their own conclusions. This type of analysis can be found in news coverage focusing on a wide variety of topics. Importantly, findings from a Pew Research survey has suggested that Americans are more likely to prefer political news coverage when interpretation is not included (Barthel \& Gottfried, 2016), however, to date no research has investigated the impact of this type of reporting on trust or credibility perceptions. Further, political affiliations in the U.S. are often characterized by Republican and Democratic leaning tendencies and have the potential to influence perceptions of the citizenry (Smith, 2016). Pertinent to this study, research suggests that conservatives are less likely to trust political news coverage (Jones, 2004; Lin et al., 2016). 
Building on this limited body of scholarship, this study seeks to expand on the findings of the 2016 Pew Research report on the relationship between political news coverage preference and the exclusion of interpretation within journalism (Barthel \& Gottfried, 2016). Additionally, a goal of this study is to better understand the role political ideology plays on important outcomes such as perceptions of trust and credibility with respect to political news coverage. This study will set itself apart from existing research on media distrust in two key ways. First, this study will seek to understand factors that may lead people to trust political news coverage as opposed to why they do not. Second, while the methodology of many studies within this field have relied upon panel surveys and information from the National Election Survey (e.g., Hopmann et al., 2015; Jones, 2004; Lee, 2010), this study will utilize a survey-embedded experiment to empirically test the relationship between the aforementioned variables.

\section{Political Coverage and Trust}

While the extant literature exploring distrust in political news coverage is robust, this study will focus on two relevant areas of scholarship to include the context or environment in which the news is produced, and the content of the coverage. As it relates to the environment in which the news is being produced, one key area of concentration is the intense level of political polarization in the U.S. One illustration of this political polarization is legislative gridlock in the U.S. As recently as 2012, gridlock influenced 75 percent of the important issues on Washington's agenda (Binder, 2014). In addition to the polarization experienced on the government level, studies have found that Hillary Clinton and Donald Trump supporters, and more broadly Democrats and Republicans cannot agree on basic facts (Barthel \& Gottfried, 2016; LaLoggia, 2018).

The tone of the mass media also plays a role in this political climate. During the 2016 presidential election and in the months following, negativity within the news dominated coverage (Journalists Resource n.d.; Patterson, 2017). There is no doubt that this is in part because 
negative news coverage often elicits more of a reaction than positive news coverage (Heath, 1996; Soroka \& McAdams, 2015). Throughout the 2016 general election, negative news reports accounted for 77 percent of Donald Trump's coverage and 64 percent of Hillary Clinton's coverage (Patterson, 2017). Topics such as immigration, Muslims, health policy and the economy also received overwhelmingly negative coverage (Mitchell, Gottfried, Stocking, Matsa, \& Grieco 2017; Patterson, 2017). The relevance of negativity within the news cannot be underscored in this study as it has been said that this is a direct result of an interpretive style of reporting (Patterson, 1996). This body of research highlights the importance of both political ideology and a negative political climate when considering perceptions of political news coverage. Thus, this study will explore the relationship of political ideology to trust and perceptions of credibility in political news coverage.

A second important area of scholarship related to trust in political news is the content of coverage. In particular, scholars have examined at length the effects of framing on distrust in political news coverage (Becker, 2011; Hopmann et al., 2015; Shen et al., 2014). For example, studies exploring the use of comedy in political news coverage (Becker, 2011; Guggenheim, Kwak, \& Campbell 2011; Hoffman \& Young, 2011) have found a positive correlation between comedic framing and increased trust (Becker, 2011). Other studies have focused on strategic game framing (Hopmann et. al, 2015; Lawrence, 2000; Mutz, 1995), which identifies who is winning or losing in a political race by focusing on who is ahead in the polls, campaign strategies and individual politicians' motives behind decision making (Hopmann et. al, 2015). Findings from Harvard's Shorenstein Center on Media, Politics, and Public Policy found that during the 2016 U.S. presidential election, the "horse-race" topic accounted for 42 percent of campaign coverage (Patterson, 2017), which serves as a prevalent example of strategic game framing in the U.S. Further, results from a study conducted in Europe showed that "exposure to media framing of politics as a strategic game leads to decreasing media trust, a pattern that 
holds for all media except the tabloids" (Hopmann et al., 2015, p. 792). Additional work related to the content of political news coverage has examined the impacts of narrative usage within reporting on specific issues (Shen et al., 2014). While the impacts of framing on media trust have been subject to a variety of research, the role of interpretive journalism and its effect on content within political news coverage is in need of further empirical investigation. Before exploring interpretive journalism further, it is first important to elaborate on trust and credibility, especially in a political news context.

\section{Defining Trust}

While scholarship in the area of political communication is vast, there are two common issues that this study recognizes and addresses in its design. First, a common issue with previous research on media distrust has been the inability for scholars within this field to set forth a consistent definition of trust within the context of political communications (Becker, 2011; Hanitzsch et al., 2018; Hopmann et al., 2015; Johnson \& Kaye, 2009; Jones, 2004). A further problem within this field is that trust and credibility at times have been used synonymously while they represent distinctly different constructs (Carr, Barnidge, Byung Gu Lee, \& Tsang, 2014; McComas \& Trumbo, 2001; Singletary, 1976). The concepts of trust and credibility have long been studied in tandem within the context of the news media (Johnson \& Kaye, 2009; Karlson, Clerwall \& Nord, 2014; Kohring \& Matthes, 2007; Renn \& Levine, 1991). While some scholars have noted that trust and credibility do not stand for mutually exclusive concepts (Kohring \& Matthes, 2007), others operationalize these variables and distinct constructs. To add conceptual clarity in the context of this study, trust will be recognized as an affective variable based on past research indicating trust allows people a mechanism to deal with risk (Kohring \& Matthes, 2007), that trust can be deep seated in cultural values (Tsfati \& Airley, 2013) and that trust relies upon the goodwill of another person (Jones, 2005). Additionally, credibility will be recognized as a cognitive variable as findings have indicated that credibility impacts information retention 
(Karlsson et al., 2014), that credibility is assigned based on perceived performance (Renn \& Levine, 1991) and that credibility is associated with the perceived veracity of the communication (Appelman \& Sundar, 2016). Credibility of news coverage will be further addressed in the next subsection.

Many definitions are available when investigating the conceptualization of trust in the context of political communication. For instance, one commonly used definition defines the variable as "the degree to which people perceive that government is producing outcomes consistent with their expectations" (Hetherington, 2005, p. 9). Another study posits that trust is a "psychological state comprising the intentions to accept vulnerability based on positive expectations" (Rousseau, Sitkin, Burt, \& Camerer, 1998, p. 395). These two definitions represent a mere sample of the wide variety of trust definitions in existence (for a review see Müller, 2013) and will not be selected in this study as one pertains specifically to the government, and the other focuses on the psychological aspect of trust. In the context of this particular study, trust will be defined as "the belief that the perceived institutional performance conforms to the expectations of the individuals" (Müller, 2013, p. 40) as it focuses on societal dynamics of media institutions that contribute to trust as opposed to "social-psychological accounts of trust" (Müller, 2013, p. 41). Further, this research will rely on a trust scale that is composed of selectivity of facts, accuracy of depictions and journalistic assessment (Kohring, \& Matthes 2007), as it specifically addresses the measurement of media trust. These components are derived from the societal function of the news media and will allow the study to capture the reader's full assessment of the news content assigned.

\section{Credibility}

Often involved in the discussion of distrust in political news coverage is that of media credibility. The terms credibility and trust have regularly been used by researchers to define one another (e.g., Carr et al., 2014; McComas \& Trumbo, 2001; Singletary, 1976). For decades, 
organizational communication, as well as communication and marketing researchers have studied the relationship between credibility and trust. In some instances, studies have identified trust as a predictor of credibility (Gaziano \& McGrath, 1986; Johnson \& Kaye, 2009), while others have found that a strong correlation exists between trusting beliefs and credibility (McKnight \& Kacmar, 2007). More common are findings indicating credibility is an antecedent to trust (Mayer, Davis \& Schoorman, 1995; Eastlick \& Lotz, 2011). Building on these findings, the present study will seek to support the notion that credibility is a predictor of trust in the context of perceptions of political news coverage.

To better understand the conceptualization of credibility, two key bodies of research informed this study. The first is scholarship focused on the development of a measurement model to assess perceptions of media credibility (Appelman \& Sundar, 2016; McComas \& Trumbo, 2001; Whitehead, 1968). The second body of scholarship focuses on the factors that predict credibility in a political communication context (Car et al., 2014; Cole \& Greer, 2013; Johnson \& Kaye, 2009; Kiousis, 2006; Slater \& Rouner, 1996; Sundar, 1998; Sundar, 1999).

In the last 50 years, understanding of the proper ways to measure credibility has taken great strides (Appelman \& Sundar, 2016; Gaziano \& Mcgrath, 1986; Johnson \& Kaye, 2009; McComas \& Trumbo, 2001; Whitehead, 1968). In particular, researchers have separately studied the key components of credibility, to include source, medium and message. Initially, credibility scales focused on source credibility through the use of semantic differentials including items such as "fair," "respectful" and "professional" (Whitehead, 1968). One reason for the emphasis on source in credibility research is that the content and target audience has often been predetermined by the information provider (Wathen \& Burkell, 2002). For example, one study indicated that those who previously held distrust in the government were more likely to find neither Fox News nor CNN to be credible, while those who previously trusted the government found both sources to be credible (Stroud \& Lee, 2013). Later, measures for 
medium credibility were developed to assess topics like respondents attitudes towards newspapers (Gaziano \& Mcgrath, 1986). Pertaining to both source and medium credibility, research has investigated topics such as credibility of blogs (Johnson, Kaye, Bichard \& Wong, 2007; Chesney \& Su, 2009; Johnson \& Kaye, 2009; Juffinger, A., Granitzer, M., \& Lex, 2009; Kang, 2010), the impacts of peer endorsement on perceived credibility (Van Reijmersdal, Neijens \& Smit, 2010; Cole \& Greer, 2013) and the perceived credibility of mainstream vs. citizen journalism (Carr et al., 2014).

What has been less studied is that of message or content credibility. It is important to note that this study uses the terms content and message interchangeably when discussing political news coverage as they are afforded such similar measures (Pressgrove \& Kim, 2018). As this study will explore the role of interpretive journalism in political coverage, message credibility, rather than source and medium, is most important. Specifically, message credibility can be defined as "an individual's judgement of the veracity of the content of communication" (Appelman \& Sundar, 2016, p. 63). Research on message credibility, or the content of the political communication, has found that news stories that included quotes were rated higher in credibility than those that did not (Sundar, 1998) and that the use of multimedia had a positive impact of source credibility but did not yield higher levels of perceived message credibility (Kiousis, 2006). It is evident that a numerous factors can influence the perceived content credibility of a news piece.

As previously stated, trust and credibility are separate constructs, however, the relationship between the two is especially important in the evaluation of political news coverage. As stated by Appelman \& Sundar (2016), journalism depends on the trust of readers. In an era characteristic of countless sources of news and information, the loss of credibility can have detrimental effects on a journalist or publication. Building on prior research that indicates that credibility predicts trust (e.g., Eastlick \& Lotz 2011; Mayer et al.,1995; McKnight \& Kacmar, 
2007), and a desire to evaluate the predictive value of content or message credibility toward trust in political coverage, the following research hypothesis is proposed.

H1: High perceptions of message credibility will predict high levels of trust in political news coverage.

\section{Interpretive Journalism}

Central to the aims of this study is the concept of interpretive journalism. To date, research on this topic has not examined the effects of interpretive journalism on perceived trust and credibility within the context of political news coverage. This study will employ the definition of interpretive journalism developed by Salgado \& Strömbäck (2011).

Interpretive journalism is opposed to or going beyond descriptive, fact-focused and source-driven journalism. On the story-level of analysis, interpretive journalism is characterized by a prominent journalistic voice; and by journalistic explanations, evaluations, contextualization, or speculations going beyond verifiable facts or statements by sources. It may, but does not have to, also be characterized by a theme chosen by the journalist, use of value-laden terms, or overt commentary (p. 154).

With a clear understanding of how interpretive journalism is defined, two bodies of research will inform this study. First, it is imperative to examine the intended role of a journalist. Second, prior research on various types of interpretative journalism lends insight to the topic at hand.

The role of journalism must be included in this discussion as it helps indicate preceding expectations regarding interpretation within journalism. While there is no official creed that journalists must adhere to, there are bodies of work that can be drawn from to infer what the role of the American journalist should be. Within the Elements of Journalism, it is not specifically addressed whether or not journalists should analyze the news they are covering (Kovach \& Rosenstiel, 2001). The Commission on the Freedom of the Press, known for their investigation of the role of the press in American society, stated in their findings that a requirement of the 
press is to present, "a truthful, comprehensive, and intelligent account of the day's events in a context which gives them meaning" (Commission on the Freedom of the Press, 1947, p. 21). If journalists subscribe to this requirement presented by the Commission, interpretation of the news may be necessary to give the news meaning. An additional perspective is that of the Society of Professional Journalists' code of ethics, which does not dissuade journalists from interpreting the news, but stresses accuracy when doing so (Society of Professional Journalists, n.d.).

Also important to the discussion of interpretive journalism and the role of journalists in the context of political news coverage are studies that have focused on the style in which the news is being reported. There has been a variety of research conducted on both media bias (e.g., Budak, Goel \& Rao, 2014; Feldman, 2010; Gunther, 1992) and objectivity (e.g., Praveen Kumar, 2016; Mothes, 2017; Muñoz-Torres, 2012). Most relevant to the present study, one experiment found that readers are likely to "[characterize] objective texts as lacking purpose, or having a merely descriptive or expository purpose, and biased texts as exhibiting explicit interpretive or argumentative purposes" (Cramer \& Eisenhart, 2014, p. 300). This finding is particularly important for two key reasons. First, this will help shape the stimuli being utilized in the following experiment. Second, while these findings do not allow for the conclusion that biased texts and interpretive texts are synonymous, they do showcase the relationship between the two.

A limited body of research has focused on interpretive journalism. As emphasized by Salgado \& Strömbäck (2011) in an early examination of interpretive journalism, it was said that "interpretation provides the theme, and facts illustrate it" (Patterson, 1993, p.85). One key study found that in the U.S., interpretive journalism depends more on "experts, direct quotations, and considerations of pros and cons" (Esser \& Umbricht, 2014, p. 244), compared to that of European countries. Further, as previously stated, findings from Pew Research Center indicate 
that U.S. citizens prefer political news coverage with no added interpretation (Barthel \& Gottfried, 2017). Surprisingly, in an investigation of media interpretation, it was found that message content was responded to similarly whether it came from a politician or the media. This was in contrast to source in which political messages were perceived as more convincing and likely to inspire optimism when presented by politicians as opposed to newspapers (Fogarty \& Wolak, 2009).

Though research on interpretive journalism has been limited, and the credos that journalists follow do not clearly weigh in on this issue, the available research on interpretive journalism has not explored trust or credibility. However, the preferences identified by the Pew Research Center study indicate a level of disdain among Americans for interpretive journalism within political news coverage (Barthel \& Gottfried, 2017). Thus, the author poses the following hypotheses.

H2a: The absence of interpretation within news content will lead to increased levels of trust in political news coverage.

H2b: The absence of interpretation within news content will lead to increased levels of credibility in political news coverage.

\section{Political Affiliation}

When considering factors of trust in political news coverage, political affiliation cannot be overlooked. Political affiliation refers to the political party that citizens identify with, capable of influencing ideological thinking and even behavior (Dalton, 2016). The relevance of political affiliation to trust in political news coverage can be characterized by the way that political ideologies influence not only the coverage that people trust, but also the news sources that people subscribe to. The implications of political affiliation have long been the subject of research (e.g., Campbell, Converse, Miller \& Strokes, 1969; Greene, 1999; Goren, 2005; 
Carsey \& Layman, 2006). However, a potential relationship between political affiliation and trust in interpretive journalism has been overlooked by previous research.

As credibility is separate from trust, it is important to examine specific studies exploring each in turn. First to consider credibility. Cable television networks have also come into question regarding the relationship between party identification and political news coverage (Dellavigna \& Kaplan, 2006; Morris, 2007; Coe, Tewksbury, Bond, Drogos, Porter, Yahn \& Zhang, 2008). For instance, data from the Cooperative Election Study found that liberals tended to find CNN to be more credible while conservatives found Fox News to be more credible (Stroud \& Lee, 2013). In support of this, it has been found that U.S. citizens perceive news sources to be more credible when they are either consistent with pre-existing attitudes or could be deemed as neutral sources (Metzger, Hartsell \& Flanagan, 2015; Zanna \& Del Vecchio, 1973). Again, the prevalence of polarization in the U.S. should be noted as it has been found that partisans evaluate new stories as more credible when they are in line with their ideological thinking (Kim \& Pasadeos, 2007).

Another relevant area of inquiry by scholars has probed the general relationship between party identification and trust in the news media. Research has indicated that voters who distrust the media are more likely to minimize the significance of the news during political campaigns, opting to rely on their own partisan preferences (Ladd, 2010). Relatedly, other research suggests that pre-existing individual preferences and ideologies may influence media distrust (Lee, 2010). Unsurprisingly, research has found that individuals who thought their political party was negatively portrayed by the news, had a positive bias towards their party (Lin et al., 2016).

Also relevant to the discussion of the effects political affiliation has on trust in political news coverage are individuals who identify as Republicans or conservatives (Eveland \& Shah, 2003; Jones, 2004; Morris, 2007; Swift, 2016; Barthel \& Mitchell, 2017). One study examining 
American citizens relationship with the media found that Republicans were distrusting of mainstream news, especially if they listened to political talk radio (Jones, 2004). While a variety of studies have highlighted a decline in media trust over time (e.g., Global Trust Index, 2018; Hanitzsch et al., 2018), this decline in trust is especially interesting on a per party basis. According to results of a Gallup Poll, Republican trust in the media dropped from 32 percent to just 14 percent between 2015 and 2016 in the wake of the Trump vs. Clinton presidential campaign (Swift, 2016). This decline in trust is quite drastic compared to that of Independents and Democrats dropping from 33 to 30 percent and 55 to 51 percent respectively (Swift, 2016). Further, in 2017 Pew Research found that just 11 percent of Republicans trusted information from national news sources (Barthel \& Mitchell, 2017). Perhaps most important to this study, it has been found that personal and political cynicism, as well as Republican partisanship serve as predictors of distrust in the media (Lee, 2010).

Former research has clearly pointed to the notion that Republicans and conservatives in general are less trusting of the news media than their Democrat and liberal counterparts (Hanitzsch et al., 2018; Jones, 2004; Swift, 2016). This trend of distrust is especially observable in the wake of the 2016 presidential election (Barthel \& Mitchell, 2017; Swift, 2016). With that said, an area that has lacked investigation is the effects of interpretive journalism on selfidentified Republicans and conservatives' trust in the media. To expand on the indications of conservative distrust in the media coupled with a desire to determine the impacts of interpretive journalism on this distrust, the following research hypotheses are advanced.

H3A: Conservatives presented with an interpretive journalism article will report lower levels of trust in the political news coverage than their liberal counterpart.

H3B: Conservatives presented with an interpretive journalism article will perceive the political news coverage to be less credible than their liberal counterpart. 


\section{Method}

To test this study's proposed hypotheses, this experiment employed a 2 (interpretive journalism; fact-based journalism) x 2 (political ideology: conservative leaning;liberal leaning) factorial design and was administered via Qualtrics. The dependent variables in this study are credibility and trust. To conduct this study, existing political news coverage focusing on specific topics were modified to exemplify journalism that was highly interpretive, and journalism that was strictly factually based. More specifically, participants were randomly assigned one article to read featuring either interpretive journalism or strictly fact-based journalism. Following the reading of the article, participants answered a series of questions which gauged their perceived levels of trust and credibility, as well as their political ideology and other demographic variables.

This author recognizes that this experiment relied upon the quasi-experimental variable of political ideology even though the literature review was largely informed by research on political affiliation. In an effort to rely less heavily upon partisan preferences, and instead to accentuate the value of conservative/liberal learning tendencies, participants were asked to express their political ideology as opposed to their political party (Jost, Nosek \& Gosling, 2008). This variable is necessary to properly assess the perceptions conservatives and liberals have of interpretive journalism. Additionally, internal validity was controlled for by randomly assigning participants to the two content treatment groups.

\section{Pretest}

Prior to administering this study's survey-embedded experiment to Amazon's Mechanical Turk (MTurk) workers, a convenience sample pretest was conducted which was primarily composed of undergraduate students at West Virginia University. The first round of pretesting consisted of 137 participants prior to removing incomplete entries and individuals who failed the attention checks. Analysis of the manipulation checks from this pretest did not yield statistically significant differences. Therefore the stimuli was revised to better represent the 
characteristics of interpretive journalism and fact-based journalism by adding headlines and pull quotes to both articles. The second round of pretesting consisted of 25 participants and resulted in statistically significant differences between groups for the manipulation checks.

The pretesting accomplished two goals. First, the primary purpose of the pretest was to ensure that the manipulation of interpretive journalism was being correctly perceived. Second, the pretest allowed respondents to provide general feedback on the flow of the survey as well wording of questions. Additionally the pretest helped to assess the time necessary to complete the experiment. Revisions based on the pretesting included rewording an attention check for additional clarity, adding a "some college" option when gauging education levels and better expressing that questions should be answered to the best of the participants ability even if they do not have prior knowledge of the topic of the article. On average the pretest took 15 minutes and 42 seconds.

\section{Stimuli}

To avoid potential bias that may come with prior knowledge on a political topic, the articles displayed reported on a fictional county commission election. No real names were used, and no political parties were referenced. To assure that no bias can be derived from the news source and that they were presented in the same manner, the name of the news outlet, the author and the date were all omitted. The treatment articles were inspired by articles from CNN on the confirmation of Supreme Court Justice Brett Kavanaugh. The articles were modified to fit this context. To manipulate the key variable of content type, one article in this study was designed to represent interpretive journalism, while the other represented fact-based journalism. While both articles provided a general background on the election and swearing in of the County Commissioner, they deviated in terms of composition. The modified articles can be found in Appendix A. 
There were several defining features in the interpretive article. First this article was designed to showcase the emotions felt by the constituency following this election. Second, multiple quotations were included which allows the style of reporting to be more interpretive (Sundar,1998). Additionally, this article suggests an expedited investigation on a candidate despite unsubstantiated charges. These implications go beyond verifiable facts which is often an aspect of interpretive journalism (Salgado \& Strömbäck's, 2011). In contrast, the factuallybased article can be characterized as cut and dry. The article provides both an overview of facts regarding the election/swearing in, as well as a timeline of events. This article allowed for the reader to draw their own conclusions on the topic.

\section{Participants and procedures}

To conduct this experiment, the author relied on MTurk. The primary purpose of MTurk is to provide an outsourced distributed workforce to virtually perform tasks (Amazon Mechanical Turk, 2018). The MTurk service provided by Amazon is utilized for a variety of roles to "include anything from conducting simple data validation and research to more subjective tasks like survey participation, content moderation, and more" (Amazon Mechanical Turk, 2018, para 1). MTurk is able to recruit a diverse body of workers through monetary incentives. In this instance MTurk was utilized to recruit participants to complete this study's online experiment.

To ensure a quality data set, the present study utilized MTurk's worker requirements. While this study did not require respondents to be "Master workers," it did require the respondents to have a Human Intelligence Tasks (HIT) approval rating of 98 percent or higher. Additionally, as a point of emphasis in this research is political ideology, this study stipulated that half of the respondents identified as conservative and the other half identified as liberal. Participants were provided $\$ 0.75$ for their participation. The Qualtrics' randomizer feature, randomly assigned participants to one of two treatment conditions, each consisting of a single 
political news article based on the same fictional topic. Participants were instructed to read the article and then answer a series of questions aimed at measuring study variables.

To ensure that this study was in compliance with IRB it is important to note that MTurk workers had the ability to remain completely anonymous through unique user IDs that are only accessible by Amazon. Additionally, MTurk workers always have the ability to choose which HIT they would like to complete making this study completely voluntary (Amazon Mechanical Turk, 2018). The sample consisted of individuals who were 18 years or older and resided in the U.S.

The average reading rate for U.S. adults is 300 words per minute (Nelson, 2012) and the articles displayed in this study are less than 400 words each. Qualtrics estimated that this survey would take approximately 15 minutes to complete, and the pretest confirmed. With this in consideration, along with an effort to not rush participants, participants were given a total of 35 minutes to complete this study before it timed out and their answers are discarded.

Demographics. The original sample drawn from MTurk was composed of 191 participants. Of the 191 participants, 172 participants were valid for analysis. Participants were only removed from this study if they failed one of the attention checks or if they submitted an incomplete questionnaire. All participants in this study were 18 years of age or older and resided in the United States. The average participant age was 46 years $(S D=13.1$, range $=21-75)$. With respect to ethnicity, 143 respondents identified as white (83.1\%), 11 identified as Black or African American (6.4\%), nine identified Asian or Pacific Islander (5.2\%), six identified as Hispanic or Latino (3.5\%), two identified as other (1.2\%) and one identified as Native American $(0.6 \%)$. The gender of participants was relatively evenly split with a slight majority of participants, $n=98$ identifying as female (57\%) and 73 participants identified as male (42.4\%). As political affiliation was a point of emphasis in this study, 81 participants $(47.1 \%)$ identified as liberal or liberal leaning, 78 identified as conservative or conservative leaning $(45.4 \%)$ and 13 identified as neutral (7.6\%). 


\section{Measures}

This study consisted of two independent variables, a quasi-experimental variable and two dependent variables. The first independent variable of content type refers to the article that participants are assigned to read: one article featured interpretive journalism while the other featured fact-based journalism. The quasi-experimental variable of political ideology consisted of self-identified conservative leaning and liberal leaning individuals measured on a 7-point semantic differential scale, with 1 representing liberal and 7 representing conservative. The dependent variables of this research consisted of perceived content credibility of political news coverage and perceived content trust in political news coverage. The full questionnaire can be found in Appendix C.

\section{Quality, attention and manipulation checks}

This study asked several questions to ensure both quality responses from participants and that the manipulation was being perceived as intended. First, regardless of which condition the participant was assigned to, they were asked to indicate what the article was about. The answers to this question included "a county commissioner election," "Affirmative Action," "a military conflict" and "immigration into the U.S." If any answer was selected other than "a county commissioner election," the participant's responses were not included in the analysis. Next, after reading the assigned article, participants were asked whether they had knowledge of this election prior to reading the article. If a participant selected yes, their responses were discarded as the election is fictitious. Also, participants were asked near the midpoint of the survey to select the 'agree' option on a 7-point Likert scale. Any participants who selected an answer other than 'agree' were not included in the analysis. A total of 19 participants were removed from the analysis of this study. Finally, to assess the quality of the manipulation, respondents were asked to assess a series of six statements on 7-point Likert scale ranging from "strongly disagree" to "strongly agree" with a "don't know" option. These statements were used to gauge 
the level of interpretation in the stimuli as perceived by study participants. It should be noted that none of the participants selected the "don't know" option for any of the manipulation checks. The statements are listed below.

Participants responded to the statement, "The article displayed only presented facts without interpretation" on a 7-point Likert scale ranging from strongly disagree (1) to strongly agree (7). An independent $t$-test was used to examine the content manipulation, $t(167.1)=6.16$ and $p=0.00$. Results of the participants who were assigned to the fact-based condition were $(M$ $=5.02, S D=1.43$ ) while the results of the participants who were assigned to the interpretive condition were $(M=3.6, S D=1.63)$. Thus, the manipulation was successful.

Participants responded to the statement, "The article went beyond simply stating facts and interpreting their meaning" on a 7-point Likert scale ranging from strongly disagree (1) to strongly agree (7). An independent $t$-test was used to examine the content manipulation, $t(170)$ $=-4.74$ and $p=0.00$. Results of the participants who were assigned to the fact-based condition were $(M=3.5, S D=1.73)$ while the results of the participants who were assigned to the interpretive condition were $(M=4.72, S D=1.7)$. Thus, the manipulation was successful.

Participants responded to the statement, "This article includes value-laden terms that imply the journalist opinions" on a 7-point Likert scale ranging from strongly disagree (1) to strongly agree (7). An independent $t$-test was used to examine the content manipulation, $t(170)$ $=-6.2$ and $p=0.00$. Results of the participants who were assigned to the fact-based condition were $(M=3.5, S D=1.6)$ while the results of the participants who were assigned to the interpretive condition were $(M=4.9, S D=1.6)$. Thus, the manipulation was successful.

Participants responded to the statement, "This article includes speculations from the journalist" on a 7-point Likert scale ranging from strongly disagree (1) to strongly agree (7). An independent $t$-test was used to examine the content manipulation, $t(169)=-6.84$ and $p=0.00$. Results of the participants who were assigned to the fact-based condition were $(M=3.31, S D=$ 
1.7) while the results of the participants who were assigned to the interpretive condition were ( $M$ $=5, S D=1.5)$. Thus, the manipulation was successful.

Participants responded to the statement, "This article includes overt commentary beyond verifiable facts" on a 7-point Likert scale ranging from strongly disagree (1) to strongly agree (7). An independent $t$-test was used to examine the content manipulation, $t(163.84)=-6.2$ and $p=$ 0.00. Results of the participants who were assigned to the fact-based condition were $(M=3, S D$ $=1.5$ ) while the results of the participants who were assigned to the interpretive condition were $(M=4.51, S D=1.8)$. Thus, the manipulation was successful.

The final manipulation check was measured on a single item $1=$ not interpretive, $7=$ highly interpretive, 7-point semantic differential scale. An independent $t$-test was used to examine the content manipulation, $t(170)=-5.3$ and $p=0.00$. Results of the participants who were assigned to the fact-based condition were $(M=3.44, S D=1.62)$ while the results of the participants who were assigned to the interpretive condition were $(M=4.7, S D=1.5)$. Thus, the manipulation was successful.

\section{Content Credibility}

According to Appelman and Sundar (2016), there are both key indicators and reflective indicators of content or message credibility. Thus, to measure "content credibility," this study employed semantic differential scales with a 7-point range between nine bipolar adjectives to assess key indicators $(M=4.36, S D=1.06, \alpha=.84)$. The items asked participants to express their feelings on the article they read from "not complete to complete," "not concise to concise," "not well-presented to well-presented," "not objective to objective," "not representative to representative," "not spun to spun," "no expertise to highest level of expertise," "not impactful to impactful," and "not professional to professional" (Appelman \& Sundar, 2016, p. 71). Credibility was also measured relying upon three "credibility reflexive indicators" $(M=5.07, S D=1.3, \alpha=$ .91). The items asked participant to express their feelings on the article they read from "not 
authentic to authentic," "not accurate to accurate" and "not believable to believable" (Appelman \& Sundar, 2016, p.71).

\section{Trust in the News Media}

As a means of measuring trust in the news media, the present study drew on a scale developed by Kohring and Matthes (2007). To measure perceptions of trust in news media, respondents were asked to respond to items measured on a 7-point Likert scale ranging from "strongly disagree" to "strongly agree" with an additional "don’t know" option" (Kohring \& Matthes, 2007) to assess statements about the news article they read. The complete measure of media trust typically relied upon the assessment of "selectivity of topics," "selectivity of facts," "accuracy of depictions" and "journalistic assessment." However, in this study, the four questions that predict selectivity of topics will be excluded because there is only one topic available to participants and it is fictitious, thus making this measure inappropriate in the current context. "Selectivity of facts" was measured with four items on a 7-point Likert scale ranging from strongly disagree (1) to strongly agree $(7)(M=4.12, S D=1.4, \alpha=.86)$. The items included "the essential points were included," "the focus is on important facts," "all important information regarding the election was provided" and "reporting includes different points of view" (Kohring \& Matthes, 2007, p. 245). "Accuracy of depictions" was measured with four items on a 7-point Likert scale ranging from strongly disagree (1) to strongly agree $(7)(M=5.01, S D=1.3, \alpha=$ .95). The items included "The information in the report would be verifiable if examined," "The reported information is true," "The reports recount the facts truthfully" and "The facts that I received regarding the topic are correct" (Kohring \& Matthes, 2007, p. 245). "Journalistic assessment" was measured with four items on a 7-point Likert scale ranging from strongly disagree (1) to strongly agree $(7)(M=4.57, S D=1.32, \alpha=.9)$. The items included "Criticism is expressed in an adequate manner," "The journalists' opinions are well-founded," "The commentary regarding this election consists of well-reflected conclusions" and "I feel that the 
journalistic assessments regarding the commissioner election are useful” (Kohring \& Matthes, 2007, p. 245).

\section{Findings}

Data were analyzed using Statistical Package for the Social Sciences (SPSS).

Regression analysis was conducted to investigate if high perceptions of content credibility served as a predictor of high perceptions of trust $(\mathrm{H} 1)$. As discussed above, trust is measured in four ways. First, each of the three relevant dimensions of the Kohring and Matthes (2007) trust scale were assessed, including "selectivity of facts," "accuracy of depictions" and "journalistic assessment." Additionally, the author included a single-item question that asked participants to directly indicate how much they trusted the article. This item will be characterized as "overall trust." The findings reported below and in Table 1, support $\mathrm{H} 1$.

In each instance relying upon the Appelman \& Sundar "content credibility" scale (2016), the author found statistically significant results related to the predictive value of content credibility on all dimensions of trust. As a result of regressing the "content credibility" scale (Appelman \& Sundar, 2016) against the dimensions of trust in the news media and a single-item measure there was a positive, significant slope for "selectivity of facts" $\left(\mathrm{B}=1.01 ; p=0.00, R^{2}\right.$ $\operatorname{adj}=0.59)$, "accuracy of depictions" $\left(B=0.87 ; p=0.00, R^{2}\right.$ adj $\left.=0.5\right)$, "journalistic assessment" $\left(\mathrm{B}=0.9 ; p=0.00, R^{2} \mathrm{adj}=0.52\right)$ and "overall trust" $\left(\mathrm{B}=1.12 ; p=0.00, R^{2} \mathrm{adj}=0.56\right)$.

In each instance relying upon the "credibility reflexive indicators" scale the author found statistically significant results related to the predictive value of content credibility on all dimensions of trust. As a result of regressing the "credibility reflexive indicators" scale (Appelman \& Sundar, 2016) against the dimensions of trust in the news media and the singleitem measure there was a positive, significant slope when determining "selectivity of facts" $(B=$ $0.76 ; p=0.00, R^{2}$ adj $\left.=0.49\right)$, "accuracy of depictions" $\left(B=0.81 ; p=0.00, R^{2}\right.$ adj $\left.=0.65\right)$, 
“journalistic assessment" $\left(B=0.75 ; p=0.00, R^{2}\right.$ adj $\left.=0.53\right)$ and "overall trust" $(B=0.98 ; p=$ $0.00, R^{2}$ adj $\left.=0.64\right)$.

In each instance relying upon the single item measure of "overall credibility" the author found statistically significant results related to the predictive value of content credibility on all dimensions of trust. As a result of regressing the single item measure of "overall credibility" against the dimensions of trust in the news media and a single item measure, there was a positive significant slope when determining "selectivity of facts" $\left(B=0.76 ; p=0.00, R^{2}=0.56\right)$, “accuracy of depictions" $\left(B=0.76 ; p=0.00, R^{2}\right.$ adj $\left.=0.67\right)$, "journalistic assessment" $(B=0.73$; $p=0.00, R^{2}$ adj $\left.=0.58\right)$ and "overall trust" $\left(B=0.96 ; p=0.00, R^{2} \operatorname{adj}=0.69\right)$.

Table 1

The Predictive Value of Credibility on Trust

Selectivity of Facts Accuracy of Depictions
Journalistic Assessment

\section{Overall Trust}

\begin{tabular}{|c|c|c|c|c|c|c|c|c|c|c|c|c|}
\hline Variable & $B$ & $p$ & $R^{2}$ adj & $B$ & $p$ & $R^{2}$ adj & $B$ & $p$ & $R^{2}$ adj & $B$ & $p$ & $R^{2}$ adj \\
\hline $\begin{array}{l}\text { Content } \\
\text { Credibility }\end{array}$ & 1.01 & 0.00 & 0.59 & 0.88 & 0.00 & 0.5 & 0.9 & 0.00 & 0.52 & 1.12 & 0.00 & 0.56 \\
\hline $\begin{array}{l}\text { Credibility } \\
\text { Reflexive } \\
\text { Indicators }\end{array}$ & 0.76 & 0.00 & 0.49 & 0.81 & 0.00 & 0.65 & 0.75 & 0.00 & 0.53 & 0.98 & 0.00 & 0.64 \\
\hline $\begin{array}{l}\text { Overall } \\
\text { Credibility }\end{array}$ & 0.76 & 0.00 & 0.56 & 0.76 & 0.00 & 0.67 & 0.73 & 0.00 & 0.58 & 0.96 & 0.00 & 0.69 \\
\hline
\end{tabular}

To assess whether the interpretive vs. fact-based conditions had an effect on each of the dimensions used to measure perceived levels of trust in political news coverage $(\mathrm{H} 2 \mathrm{~A})$, analysis of variance was used (ANOVA). "Selectivity of facts" was significantly higher $(F=12.67 ; p=$ $0.00)$ when the article was fact-based $(M=4.78)$ versus when the article was interpretive $(M=$ 4.04). "Accuracy of depictions" was significantly higher $(F=17.97 ; p=0.00)$ when the article was fact-based $(M=5.42)$ versus when the article was interpretive $(M=4.62)$. "Journalistic 
assessment" was significantly higher $(F=13.88 ; p=0.00)$ when the article was fact-based $(M=$ 4.94) versus when the article was interpretive $(M=4.21)$. "Overall trust" was significantly higher $(F=23.45 ; p=0.00)$ when the article was fact-based $(M=5.08)$ versus when the article was interpretive $(M=3.98)$. Thus, $\mathrm{H} 2 \mathrm{~A}$ was supported.

To assess whether the interpretive vs. fact-based conditions had an effect on each of the perceived levels of credibility in political news coverage (H2B), analysis of variance was used (ANOVA). "Content credibility" was significantly higher $(F=6.21 ; p=0.01)$ when the article was fact-based $(M=4.56)$ versus when the article was interpretive $(M=4.16)$. The "credibility reflexive indicators" dimension was significantly higher $(F=9.35 ; p=0.00)$ when the article was fact-based $(M=5.36)$ versus when the article was interpretive $(M=4.77)$. "Overall credibility" was significantly higher $(F=14.24 ; p=0.00)$ when the article was fact based $(M=5.43)$ versus when the article was interpretive $(M=4.66)$. Thus $\mathrm{H} 2 \mathrm{~B}$ was supported.

Table 2

Effects of Interpretive Versus Fact-Based Coverage on Trust and Credibility Perceptions

$\begin{array}{ccccc}\begin{array}{c}\text { Variable } \\ \begin{array}{c}\text { Selectivity of } \\ \text { Facts }\end{array}\end{array} & \boldsymbol{F} & \boldsymbol{p} & \text { Fact-based } \boldsymbol{M} & \text { Interpretive } \boldsymbol{M} \\ \begin{array}{c}\text { Accuracy of } \\ \text { Depictions }\end{array} & 12.67 & 0.00 & 4.78 & 4.04 \\ \begin{array}{c}\text { Journalistic } \\ \text { Assessment }\end{array} & 13.87 & 0.00 & 5.42 & 4.62 \\ \begin{array}{c}\text { Overall Trust } \\ \text { Content }\end{array} & 23.45 & 0.00 & 4.94 & 4.21 \\ \text { Credibility } & 6.21 & 0.00 & 5.08 & 3.98 \\ \begin{array}{c}\text { Credibility } \\ \text { Reflexive } \\ \text { Indicators }\end{array} & 9.35 & 0.01 & 4.56 & 4.16 \\ \begin{array}{c}\text { Overall } \\ \text { Credibility }\end{array} & 14.24 & 0.00 & 5.36 & 4.77 \\ \end{array}$


To test the hypotheses that conservatives exposed to interpretive journalism as opposed to fact-based journalism will register lower perceptions of both trust and credibility than liberals (H3A \& H3B), this study relied upon Andrew Hayes' PROCESS Macro: "Model 1."

Multicollinearity was tested for to ensure there were no high levels of intercorrelations amongst dependent variables. For this study, a VIF threshold of 3.3 was set because the variables included in the models serve as predictors of the latent variables trust and credibility (Kock \& Lynn, 2012).

First, to test the hypothesis that conservatives presented with an interpretive article will report lower levels of trust in the political news coverage than liberals $(\mathrm{H} 3 \mathrm{~A})$, political ideology was entered as a moderator and then each of the trust dimensions were entered as dependent variables in turn. The potential existence of multicollinearity for "selectivity of facts" amongst the other dependent variables measuring trust was assessed and deemed acceptable (2.52). A non-significant political ideology $x$ type of article relationship was found $(B=-0.1 ; p=0.26)$ when "selectivity of facts" was used as the dependent variable. Because this interaction is nonsignificant, no contrast will be evaluated (Figure 1). 


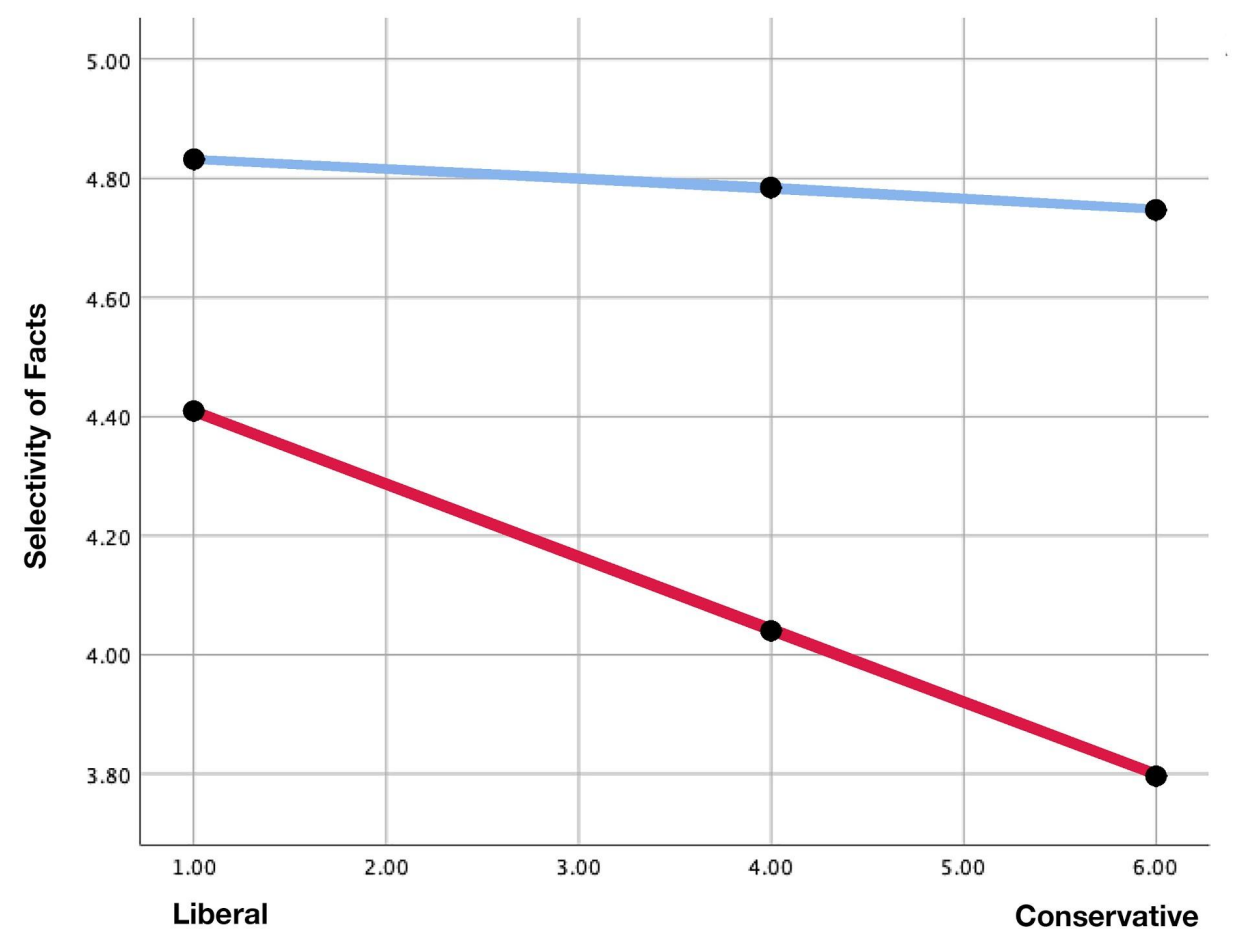

Condition

Fact-based article

Interpretive article

Figure 1. Comparison of the perception of "selectivity of facts" between fact-based and interpretive coverage.

The potential existence of multicollinearity for "accuracy of depictions" amongst the other dependent variables measuring trust was assessed and deemed acceptable (2.64). A

marginally significant political ideology $\mathrm{x}$ type of article relationship was found $(B=-.138 ; p=$ 0.098) when "accuracy of depictions" was used as the dependent variable. Because this is an exploratory study, the author decided to proceed with evaluating with contrast even though the interaction did not meet the typical significance level of .05. Consistent with our hypothesis, there was a significant effect of political ideology given a type of article where the slope test for interpretive article was significant $\left(B^{\prime}\right.$ interpretive $\left.=-0.206 ; p=0.00\right)$, and the slope test for the fact-based article was not $\left(B^{\prime}\right.$ fact-based $\left.=-0.068 ; p=0.295\right)$. This means that when the article is framed in a fact-based way there is no significant difference in the evaluation of "accuracy of depictions" between liberals and conservatives. In contrast, when the article is framed in an 
interpretive way, liberals evaluated "accuracy of depictions" in a better way than conservatives. It is important to state that the driver of the effect is not strong enough to show an interaction in the overall model. See Figure 2.

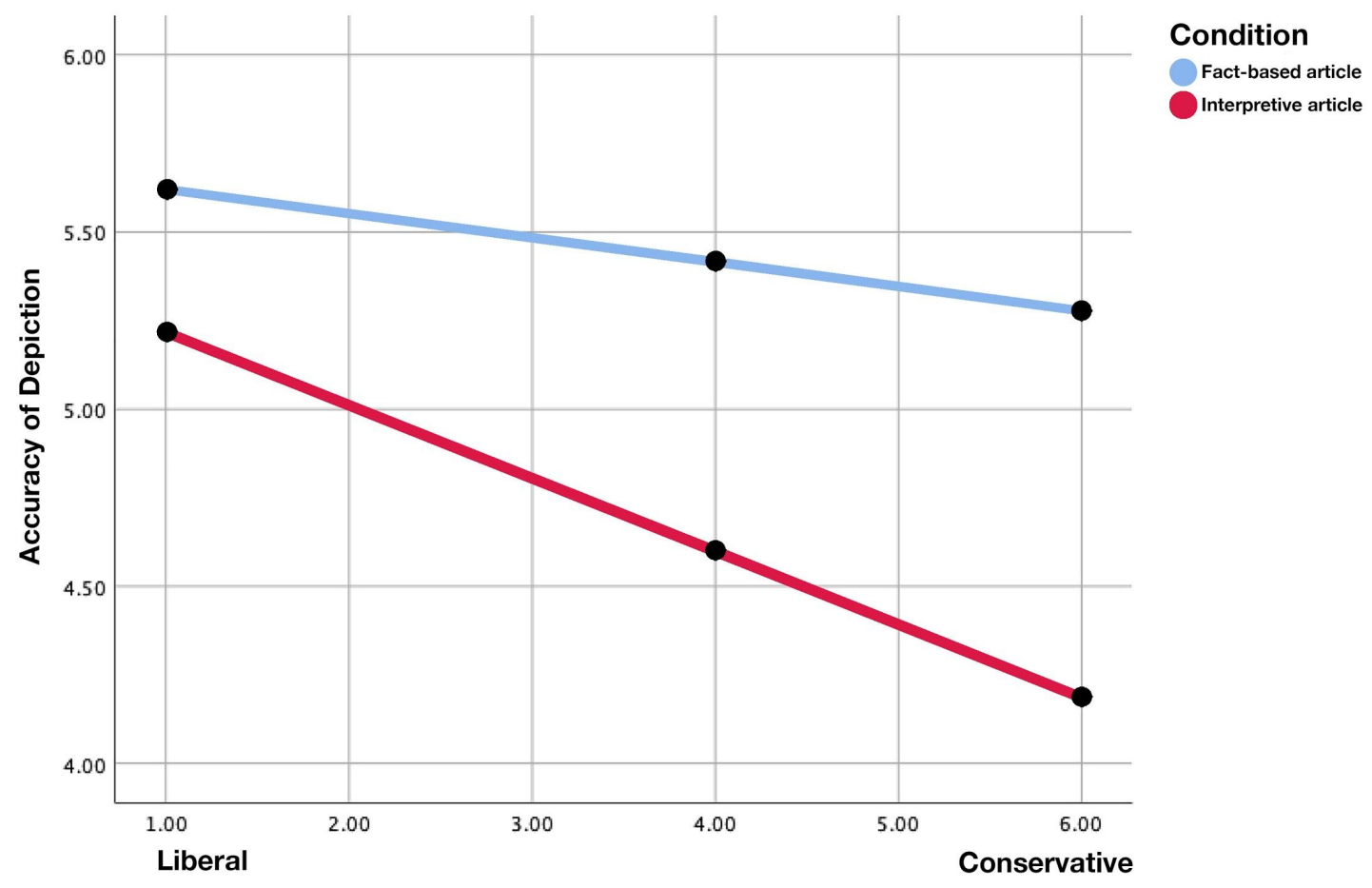

Figure 2. Comparison of the perception of "accuracy of depictions" between fact-based and interpretive coverage.

The potential existence of multicollinearity for "journalistic assessment" amongst the other dependent variables measuring trust was assessed and deemed acceptable (2.69). A non-significant political ideology $\mathrm{x}$ type of article was found $(B=.0043 ; p=0.96)$ when "journalistic assessment" was used as the dependent variable. Because this interaction is nonsignificant, no contrast will be evaluated (Figure 3). 


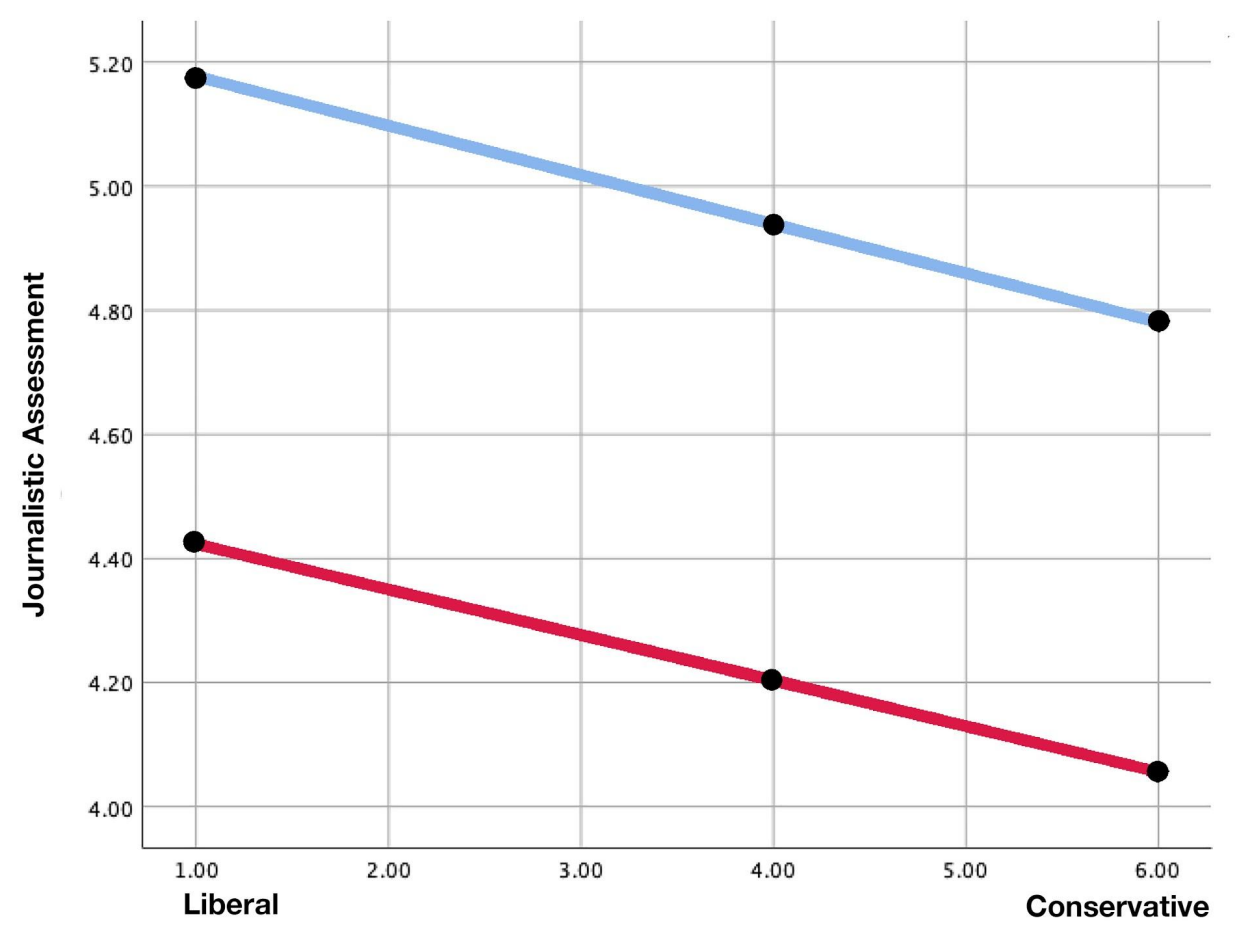

\section{Condition}

Fact-based article

Interpretive article

Figure 3. Comparison of the perception of "journalistic assessment" between fact-based and interpretive coverage.

To test the hypothesis that conservatives presented with an interpretive article will report lower levels of credibility in the political news coverage than liberals $(\mathrm{H} 3 \mathrm{~B})$, political affiliation was entered as a moderator and then each of the credibility dimensions were entered as dependent variables in turn. In this analysis, two variables were included: political affiliation and content credibility. The potential existence of multicollinearity for "content credibility" amongst the other dependent variable measuring credibility was assessed and deemed acceptable (1.00). A non-significant political ideology $x$ type of article was found $(B=0.04 ; p=0.61)$ when "content credibility" was used as the dependent variable. Because this interaction is nonsignificant, no contrast will be evaluated (Figure 4). 


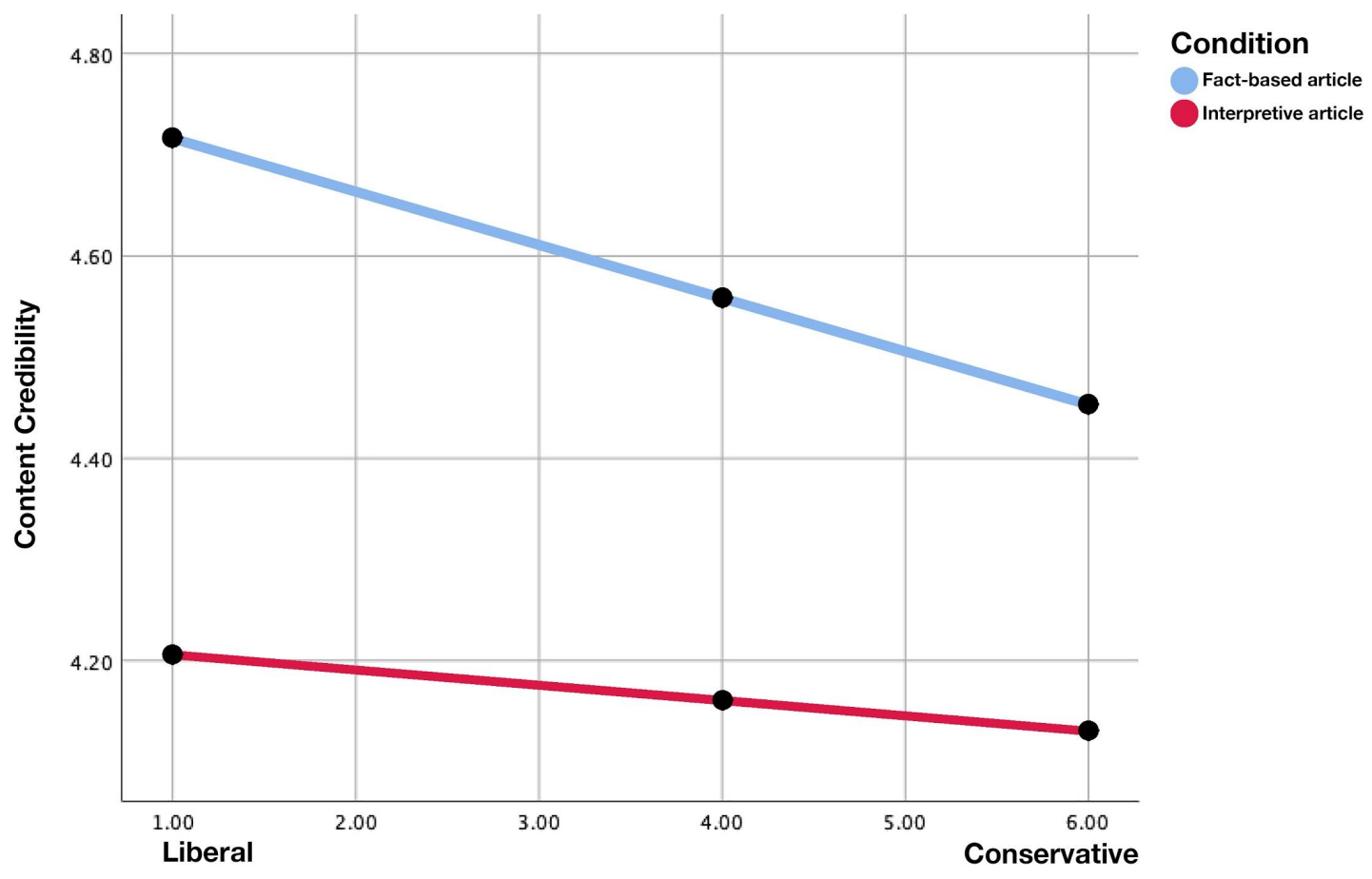

Figure 4. Comparison of the perception of "content credibility" between fact-based and interpretive coverage.

In this analysis, two variables were included: political affiliation and the content credibility reflexive indicators. The potential existence of multicollinearity for the "credibility reflexive indicators" amongst the other dependent variable measuring credibility was assessed and deemed acceptable (1.00). A non-significant political ideology $x$ type of article was found $(B=$ $0.009 ; p=0.92$ ) when the "credibility reflexive indicators" were used as the as the dependent variable. Because this interaction is non-significant, no contrast will be evaluated (Figure 5). 


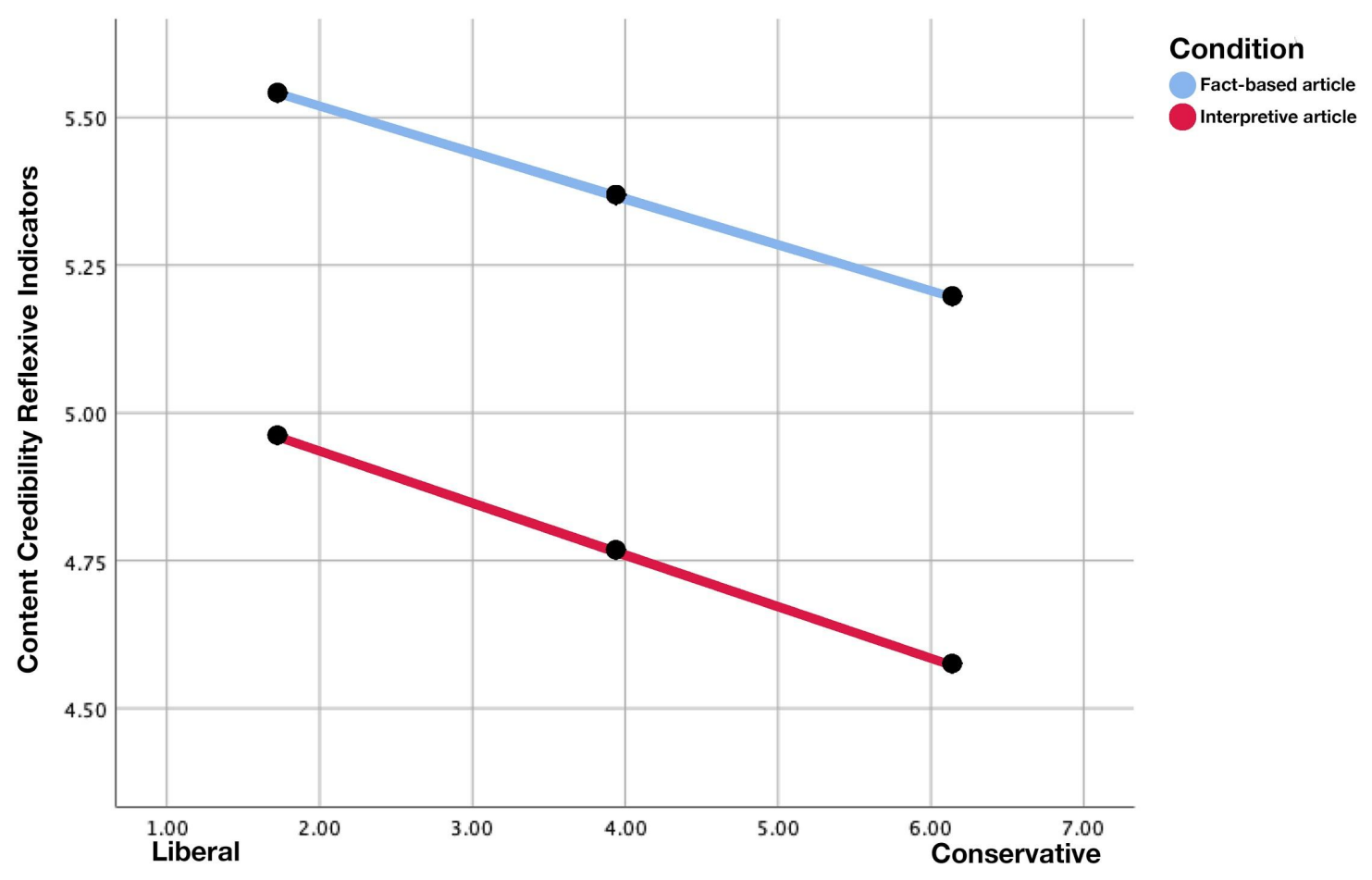

Figure 5. Comparison of the perception of "credibility reflexive indicators between fact-based and interpretive coverage.

\section{Discussion}

Amidst an incredibly tense political climate and an all-time distrust in the U.S. media, this study provides insight on trust and credibility perceptions with respect to fact-based and interpretive political news coverage. Further, it examines the impact of political ideology as it relates to trust and credibility perceptions of this news coverage. To explore these circumstances, trust and credibility were first distinctly conceptualized employing measures that recognize important dimensions of these perceptions in the context of news media. This section provides further meaning to the results listed above and sets forth implications on the manner in which news organizations should report political news coverage. 


\section{The Relationship Between Trust \& Credibility}

First, and central to this study were perceptions of trust and credibility. The author found that an effective way of separately conceptualizing the two measures was by treating credibility as a cognitive variable and trust as an affective variable. In the analysis of this study, credibility was measured by relying upon a nine-item "content credibility" scale, "credibility reflexive indicators" (Appelman \& Sundar, 2016) and a single-item measure of "overall credibility." Trust was measured relying upon a three-dimensional scale consisting of "selectivity of facts," "accuracy of depictions" and "journalistic assessment" (Kohring \& Matthes, 2007) and a singleitem measure of "overall trust."

Next, it was important to establish the relationship between the two variables. Results of this study indicate a significant relationship between credibility and trust across all dimensions. These findings support former research on the relationship between trust and credibility perceptions (Eastlick \& Lotz, 2011; Gaziano \& McGrath, 1986; Johnson \& Kaye, 2009; Mayer, Davis \& Schoorman, 1995; McKnight \& Kacmar, 2007). Broadly speaking, there are two important takeaways from the findings on this relationship in the context of political news coverage. First, these findings have implications for former researchers who have at times used the constructs of trust and credibility to define one another. These terms should not be used interchangeably, but there is undoubtedly a significant relationship between the two. Next, when considering the goals of the journalist or media organization, unique insights can be gained by relying upon distinct measures that assess the different underlying mechanisms at play in each variable. For example, the content credibility scale was the most comprehensive measure of content quality and served as a better predictor for "selectivity of facts." This dimension of trust alludes to the journalists' ability to provide objectivity and relevant information. Conversely, "overall credibility" was marginally a better predictor for assessing a journalist's commentary and criticisms incorporated in the content (journalistic assessment). It is important to recognize that 
these analyses do not account for the effects of the stimuli. The following hypotheses seek to provide meaning for how these variables interact with interpretive versus. fact-based news coverage.

\section{Interpretive vs. Fact-Based Journalism}

A primary goal of this research was to build upon a Pew Research Center report, which indicated that Americans preferred political news coverage that did not include interpretation (Barthel \& Gottfried, 2016). This study revealed that respondents exposed to fact-based journalism as opposed to interpretive journalism yielded significantly higher levels of trust and credibility across all dimensions within the context of political news coverage. This finding is especially compelling for a few reasons. First, if media organizations know that their content will be deemed as more credible and have higher perceptions of trust when it is factually-based instead of interpretive, they can tailor the writing styles of their reporters to improve these perceptions. Second, in an era where there are countless news options to choose from at any given time, producing content that people trust and deem credible could give news organizations an edge over their competitors. Finally, while research on political news coverage tends to focus on why people have low perceptions of trust and credibility, this finding provides insight on why someone might be compelled to perceive news content as credible or worthy of trust.

While the differences of trust perceptions are significant across all measures when comparing fact-based and interpretive news coverage, there was variance in the means of each individual measure from which additional insight can be derived. With respect to trust perceptions, the single-item measure representing "overall trust" and "accuracy of depictions" showed the highest level of differentiation. These differences may indicate that the adherence to a fact-based style of reporting may have considerable implications on what an individual recognizes as verifiable, correct or truthful coverage (Kohring \& Matthes, 2007). In contrast, 
"journalistic assessment" represented the lowest level of differentiation in the comparison of trust measures between fact-based and interpretive coverage. Specifically, the items that represent this dimension pertain to the journalist's criticisms, opinions, commentary and overall assessments within the coverage. An explanation for this is that the four items that made up the "journalistic assessment" dimension, essentially challenge the notion of fact-based coverage and therefore resulted in the least amount of differentiation between the two styles of coverage.

There were also significant differences across all credibility measures when comparing fact-based and interpretive news coverage. As with trust, credibility also saw variance in the means of each individual measure. The single-item measure representing "overall credibility" followed by the "credibility reflexive indicators" yielded the highest level of differentiation amongst the credibility dimensions. This finding sets forth the implication that there is a deficiency of accuracy, authenticity and believability within the context of interpretive coverage. While these preliminary findings are in need of further research, this study provides an initial framework for such an investigation and affords additional meaning to the "credibility reflexive indicators" proposed by Appelman \& Sundar (2014).

Though it was not hypothesized, an additional finding can be derived from this study that is very much related to hypotheses $2 \mathrm{~A}$ and $2 \mathrm{~B}$. The questionnaire posed the question, "I would like to read more from this news source" on a 7-point Likert scale with 1 representing strongly disagree and 7 representing strongly agree. Relying upon Univariate ANOVA, results of this question were significantly higher $(F=13.02 ; p=0.00)$ when the article was fact-based $(M=$ 4.52) versus when the article was interpretive $(M=3.65)$. Not only is this finding is consistent with hypotheses 2A and 2B but it also offers further support to the 2016 Pew Research Report (Barthel \& Gottfried). Additionally, this finding provides important insight on the relationship between how a story is presented and the future viability of a news organization. If readers wish to read more coverage from a particular source, then they are likely to pay for content and 
advertisers are more likely to place ads. Both of these factors relate to the continuing potential prosperity of the news outlet and add gravitas to these findings. Additionally, while content and target audience is often predetermined by the information provider (Wathen \& Burkell, 2012), findings from this study clearly points to the interrelated nature of source and content and the impact these variables can have on perceptions of political news coverage.

\section{Political Ideology as a Moderator of Content Perceptions}

One of the original goals of this study was to better understand how political ideology impacts important outcomes such as trust and credibility perceptions. While prior research has found that conservatives are generally less trusting of political news coverage and more cynical (Jones, 2004; Lee, 2010), this study provides new insight on how this is impacted by the content of news coverage. This study offers partial support to the notion that political ideology influences trust and credibility perceptions of interpretive vs. fact-based journalism. Specifically, the "accuracy of depictions," trust dimension showed that conservatives exhibited significantly lower levels of trust in interpretive journalism than that of their liberal counterpart. While the other trust and credibility dimensions did not yield the same significance levels, it is important to note that they were trending in the correct direction.

Though hypothesis $3 \mathrm{~A}$ and $3 \mathrm{~B}$ are not fully supported, the results of this study set forth implications that conservatives may be more trusting and perceive higher levels of credibility when viewing fact-based content. If additional research can support this notion, media organizations can use this information to deliberately target certain political demographics and population segments by altering the style of their reporting. It can be speculated that if done correctly the media organizations employing these tactics would boast higher levels of overall trust and credibility. Additionally, when considering the severity of declining partisan media distrust in recent years (Swift, 2016), prioritizing fact-based political news coverage could help curtail this trend. 


\section{Limitations}

As with all research, this study has its limitations. First, it is worth noting that a limitation of this study was the use of a fictional topic in the experimental stimuli. While it was necessary to assure that no pre-existing biases would influence perceptions of the articles, real news articles could have added more meaning to the results of the study and elicited stronger feelings from the participants. Another limitation of this study was creating stimuli that were as similar as possible but also perpetuated fact-based and interpretive characteristics. The priority in designing the stimuli was to ensure they depicted the same general topic and that they were same length. With that said, certain elements of the content had to deviate from one another. Additionally, a limitation of the study was the display of the articles. All participants viewed their assigned stimuli at the beginning of the study but were only offered one opportunity at the midpoint of the questionnaire to revisit the article. Results of the study may have varied if participants had access to the article throughout the duration of the study. Finally, a limitation of this study was the number of participants in the experiment. It is quite plausible that the lack of significance levels in $\mathrm{H} 3 \mathrm{~A}$ and $\mathrm{H} 3 \mathrm{~B}$ came as a result of the sample size.

\section{Future Research}

Moving forward, there are several avenues in which future researchers should investigate the impact interpretive journalism within the context of political news coverage. First, it would be interesting to examine the potential effects of source and medium on perceptions of trust and credibility. Additionally, future researchers should consider the use of additional political topics to increase generalizability. To that end, it would also be intriguing if a real, nonpolarizing, political topic could be incorporated into the context of this study. Once selected, these articles could still be manipulated to actualize the characteristics of interpretive and factbased journalism. Political news coverage was selected as the focus of this study because this type of content has often evoked feelings of distrust and concerns about credibility. Key findings 
on the effects of interpretive vs. fact-based journalism opens the door to questions on other types of coverage. With that said, an area in which future research should be conducted is nonpolitical news coverage. This could include examples such as natural disasters, crime or sports. If the role of the journalist is to provide meaning to the news as suggested by the Commission on the Freedom of the Press (1947), perceptions of trust and credibility should be investigated in the context of other types of coverage.

\section{Conclusion}

In closing, the present study was among the first to explore the effects of interpretive journalism on trust and credibility perceptions. Specifically, this study looked at political news coverage as it is typically the source of debate and controversy within journalism in the U.S. The findings of the experiment showed a direct relationship between trust and credibility. This relationship clearly offers support to former research within a political context, that have at times muddled the terms. Importantly, this study shows that individuals exhibit higher perceptions of trust and credibility in fact-based political news coverage as opposed to interpretive political news coverage. This finding sets forth implications for how political news coverage should be reported moving forward.

Lastly, while previous research had neglected the interaction of fact-based vs. interpretive journalism and political ideology, this study has provided new insights. Though the findings did not demonstrate acceptable levels of significance, generally speaking it is possible to say that conservatives exhibit lower levels of trust and credibility when evaluating interpretive as opposed to fact-based journalism. This finding suggests that there would be potential positive outcomes on trust and credibility perceptions by tailoring the reporting style of political news coverage for different political ideologies. Moving forward, media organizations and news outlets alike should consider a greater emphasis on facts as opposed to interpretation when reporting 
on political topics. If trust and credibility are values held in high regard, it is up to the journalist to report the news to the reader but not necessarily to interpret it for them. 


\section{Appendix A: Informed Consent Statement}

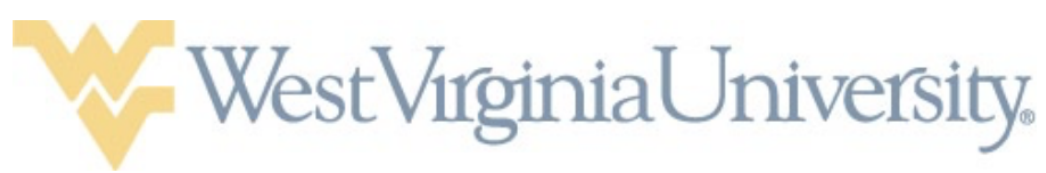

\section{Key Information for: Examining Effects of News Coverage}

We are asking you to choose whether or not to volunteer in the research described below. This page provides key information that may help you to make this decision; more detailed information can be found after this section.

Why is this research being done and what is involved?

This is an online survey designed to gauge perceptions of news coverage. This study will expand upon the current body of scholarly work news coverage by focusing on perceptions of the content within the article as opposed to source or medium. This study is especially relevant in times of low media approval.

\section{Do I have to participate and what are the risks?}

Participation in this research study is completely voluntary and you are free to withdraw from the research at any time. There is no guarantee that you will benefit from participating in this research.

Risks from participation in this study include mild frustration associated with answering questions.

\section{Who can I talk to if I have questions or concerns?}

If you have any questions or concerns about this research, you can contact Mr. Scott Siker (703-994-6015 or swsiker@mix.wvu.edu) from 9 a.m. - 5 p.m. from the Reed College of Media at West Virginia University.

For more information, please see the Informed Consent Form. 


\section{WestVirginiaUniversity.}

\section{Informed Consent $\mid$ Minimal Risk Research \\ (Version date December 20, 2018)}

Principal Investigator (PI) $\mid$ Dr. Geah Pressgrove

PI Department $\mid$ Reed College of Media

Co-Investigator(s) $\mid$ Scott Siker

Funding Source $\mid$ N/A

WVU IRB Protocol \# | Click here to enter text.

Title Effects of Interpretive Journalism on Trust in Political News Coverage

\section{Contact Persons}

you can contact Mr. Scott Siker (703-994-6015 or swsiker@mix.wvu.edu) from 9 a.m. -5 p.m. from the Reed College of Media at West Virginia University.

For information regarding your rights as a person in research or to talk about the research, contact the WVU Human Research Protection Program (HRPP) at (304) 293-7073 or by email at IRB@mail.wvu.edu.

\section{Introduction}

You, , have been asked to participate in this research study, which has been explained to you by ___ This research is being conducted to fulfill the requirements for a Master of Science in Journalism from the Department of the Reed College of Media at West Virginia University. This research is being conducted under the supervision of Dr. Geah Pressgrove.

\section{Purpose}

The purpose of this study is to study perception of news coverage. WVU expects to enroll approximately 200 subjects enrolled by WVU researchers via Amazon Mechanical Turk. A total of approximately 200 subjects at all sites are expected to participate in this study.

\section{Description of Procedures}

This study involves reading a piece of news coverage and will take approximately five minutes for you to complete. You will then be asked to fill out a questionnaire regarding the piece of political news coverage that you just read. This will take approximately 10 minutes. This study is expected to take a total of approximately 15 minutes.

\section{Risks and Discomforts}

There are no known or expected risks from participating in this part of the study, except for any mild frustration associated with answering questions. 


\section{WestVirginiaUniversity.}

\section{Alternative}

The alternative is not to participate in the study.

\section{Benefits}

There is no guarantee that you will benefit from participating in this research.

The information gained from this study may eventually benefit others.

\section{Financial Considerations}

You will be paid a single payment of $\$ 0.75$ for completing this study. The payment will be managed by Amazon's Mturk service. Subjects who submit incomplete surveys or exit the prior to completion will not be compensated.

Your information may be provided to the appropriate parties for billing and/or payment purposes. Please be advised that any compensation received for participation in a research study, including a gift card, is considered taxable income and must be reported to the IRS. If you are a WVU employee or a WVU student-employee, you are required to report the total amount of compensation received for your participation in a research study to the WVU Tax Services Office upon receipt of payment.

\section{Confidentiality}

Any information about you that is obtained as a result of your participation in this research will be kept as confidential as legally possible. Your research records and test results, just like hospital records, may be subpoenaed by court order or may be inspected by the study sponsor or federal regulatory authorities without your additional consent.

In any publications that result from this research, neither your name nor any information from which you might be identified will be published without your consent.

\section{Voluntary Participation}

Participation in this study is voluntary. You are free to withdraw your consent to participate in this study at any time and there will be no penalty to you.

Refusal to participate or your decision to stop participating will not affect your future care at West Virginia University.

In the event new information becomes available that may affect your willingness to participate in this study, this information will be given to you so that you can make an informed decision about whether or not to continue your participation. 


\section{Signatures}

You have been given the opportunity to ask questions about the research, and you have received answers concerning areas you did not understand. Upon signing this form, you will receive a copy.

\section{Participant Signature}

I willingly consent to participate in this research.

Signature of Subject or Subject's Legal Representative

\begin{tabular}{lc}
\hline Printed Name & Date
\end{tabular}

Consenting Individual Signature

The participant has had the opportunity to have questions addressed. The participant willingly agrees to be in the study.

Signature of Person Obtaining Informed Consent 
Appendix B: Stimuli

Modified Interpretive Article Inspired from- https://www.cnn.com/2018/10/06/politics/kavanaughfinal-confirmation-vote/index.html

\section{Community left in turmoil in the wake of controversial local election}

In a special election to replace retiring Lee Jones, voters elected Jordan Smith as County Commissioner on Friday. This ushered in a new majority and delivered a huge victory to the existing members of the commission. This all comes after a vicious election battle inflamed by criminal allegations against the nominee.

Shrieks of "shame, shame, shame" echoed from outside the county government building. A divided constituency voted to elect Smith by a razor thin margin of one percent, drawing questions and criticism across both the county and state. The protest underscored the vital importance of this election, one that could have sweeping consequences for upcoming spending allocations and policy decisions.

Smith was sworn in at a private ceremony at the county government building in the presence of other commission members including Lee Jones, whose seat will be taken, and Common Pleas Judge Taylor Harris. Outside, a crowd of noisy protestors gathered, and were eventually pushed back from the building's steps by police.

In the end, the current commissioners were able to use their influence across the county and state to ensure that Smith obtained the votes needed for victory. Protestors furiously accused the commission of short-circuiting efforts to examine the allegations against Smith, and of rushing the special election process forward while ignoring the complaints of

"The current
commission facilitated
one of the most
unethical, least fair,
most biased election
processes in state
history, slanting the
table from the very
beginning to produce
their desired result."
misconduct.

Following the election, one state official said the election result was "one of the saddest moments in the history of the county. The current commission facilitated one of the most unethical, least fair, most biased election processes in state history, slanting the table from the very beginning to produce their desired result."

County residents are now forced to examine Smith's political motives moving forward as they come to terms with the accusations against the new County Commissioner.

Smith's confirmation leaves the county with voters as estranged from the commission as at any time in recent memory, reflecting the cavernous divides in the country itself. It represents the culmination of a decade-long project to construct a like-minded majority on the commission which has been a defining and unifying cause in successive countywide projects.

The ferocious nature of the political battle could also have an impact on the commission itself, as Smith's vehement and politicized defense raised questions about overall temperament and fitness for office. Only time will tell the true impacts of Smith's election. 
Modified Fact-Based Article:

\section{In wake of local election, new County Commissioner is sworn in}

In a special election to replace retiring Lee Jones, voters elected Jordan Smith as County Commissioner on Friday. The special election ushered in a new majority on the commission. This election was highly publicized across the state after allegations of criminal misconduct came against Smith just weeks before Election Day.

Allegations against Smith were initially reported on four weeks before Election Day, but no legal action has been pursued. County residents then voted to elect Smith by a margin of one percent. This election represents the closest vote for a County Commissioner in the history of both the county and state. Previously the smallest margin of victory for a County Commissioner election was 2.4 percent, a low that was set more than two decades ago. In neighboring counties, the smallest margin of victory for a County Commissioner election was 3.3 percent.

As proceedings approached, protestors chanting "shame, shame, shame" could be heard outside the county government building. Because of safety

"The current commission had the same duty to conduct a fair election process as any commission has before in the state's history or ever will in the future." concerns, Smith was sworn in at a private ceremony at the county government building in the presence of other commission members including retiring Commissioner Jones, and Common Pleas Judge Taylor Harris. Outside, the protestors who were chanting and holding signs were eventually pushed back from the building's steps by police.

In the end, Smith received enough votes to win the election. In contrast to Smith's supporters, some county residents and political opponents publicly voiced at town hall last week, that the commission needs to re-examine its special election processes moving forward. The minutes recorded at the meeting indicate proposed amendments to lengthen the duration of the campaign cycle by an extra 30 days. The members of the current commission were not available for comment on these proposals.

Following the election, one state official remarked that "all elected officials have ethical responsibilities. The current commission had the same duty to conduct a fair election process as any commission has before in the state's history or ever will in the future."

Now that Smith has been sworn in, the newly elected official will begin serving on the commission at the start of next week. The Commissioner's Office reports that it has begun working on several pieces of legislation under Smith's guidance. Smith has previously served on the staff of both the state attorney general, and the governor. The first commission meeting with Smith presiding will take place next Thursday. 


\section{Appendix C: Questionnaire}

Thank you for agreeing to participate in this survey. Remember, participation is completely voluntary and you can stop at any given time if desired. Please answer all the questions to the best of your ability.

To start, please take a few moments and review the following news story and respond to a few questions.

\section{Attention Check:}

1. Please indicate the topic of the article you just read:
a. Affirmative Action
b. A county commissioner election
c. Immigration into the U.S.
d. A military conflict

\section{Quality Check:}

2. Did you have knowledge of this election prior to reading the article?
a. Yes
b. No

\section{Manipulation Check}

3. Please assess the following statement:

The article displayed only presented facts without interpretation.

(1) strongly disagree - strongly agree (7) Don't know

The article went beyond simply stating facts and interpreted their meaning.

(1) strongly disagree - strongly agree (7) Don't know

This article includes value-laden terms that imply the journalist opinions.

(1) strongly disagree - strongly agree (7) Don't know

This article includes speculation from the journalist.

(1) strongly disagree - strongly agree (7) Don't know

This article includes overt commentary beyond verifiable facts.

(1) strongly disagree - strongly agree (7) Don't know

4. In your opinion, the article was:

(1) Not interpretive - Highly interpretive (7) 
Now, we would like to ask you to answer a few questions about your feelings towards the news story you just read. Please read through each of the questions below, follow the directions and prompts on-screen.

Message Credibility:

Appelman, A., \& Sundar, S. S. (2016). Measuring Message Credibility. Journalism \& Mass

Communication Quarterly, 93(1), 59-79. doi:10.1177/1077699015606057

5. Please rate your perceptions of the article:

(1) Not Complete - Complete (7)

(1) Not Concise - Concise (7)

(1) Not Well-Presented - Well-Presented (7)

(1) Not Objective - Objective (7)

(1) Not Representative - Representative (7)

(1) Not Spun - Spun (7)

(1) No Expertise - Highest Level of Expertise (7)

(1) Not Impactful - Impactful (7)

(1) Not Professional - Professional (7)

(1) Not Authentic - Authentic (7)

\section{Content Credibility}

van Zoonen, W., \& van der Meer, T. (2015). The importance of source and credibility perception in times of crisis: Crisis communication in a socially mediated era. Journal of Public Relations Research, 27(5), 371-388.

6. The information provided was:

(1) Not Accurate - Accurate (7)

(1) Not Objective - Objective (7)

(1) Not Important - Important (7)

(1) Not Up-to-date - Up-to-date (7)

(1) Not Believable - Believable (7)

Reih and Belkin (1998) and Metzger, Flannigan, Eyal, Lemus and Mccann (2003)

7. The information provided was:

(1) Not Comprehensive - Comprehensive (7)

(1) Not Reliable- Reliable(7)

(1) Not Valid - Valid (7)

Gaziano, C., \& Mcgrath, K. (1986). Measuring the Concept of Credibility. Journalism Quarterly, 63(3), 451-462. doi:10.1177/107769908606300301

8. The information provided:

(1) Was not fair - Was fair (5)

(1) Was biased - Was unbiased (5)

(1) Did not tell the whole story - Told the whole story (5)

(1) Did not respect people's privacy - Respected people's privacy (5) 
(1) Did not watch out after people's interests - Watched out after people's interests (5)

(1) Was not concerned about the community's well-being - Was concerned about the community's well being (5)

(1) Did not separate fact and opinion - Separated fact and opinion (5)

(1) Was not concerned about public interest - Was concerned about public interest (5)

(1) Was not factual - Was factual (5)

(1) Did not have well-trained reporters - Had well-trained reporters (5)

\section{Credibility Measures}

9. This content of this article was credible.

(1) Strongly disagree - (7) Strongly agree

\section{Trust in News Media}

Kohring, M., \& Matthes, J. (2007). Trust in News Media. Communication Research, 34(2), 231252. doi:10.1177/0093650206298071

Please respond to the following statements: (1) strongly disagree - strongly agree (7)

11. The essential points are included.

(1) strongly disagree - strongly agree (7) Don't know

12. The focus is on important facts.

(1) strongly disagree - strongly agree (7) Don't know

13. All important information regarding the election was provided.

(1) strongly disagree - strongly agree (7) Don't know

14. Reporting includes different points of view.

(1) strongly disagree - strongly agree (7) Don't know

15. The information in a report would be verifiable if examined.

(1) strongly disagree - strongly agree (7) Don't know

16. The reported information is true.

(1) strongly disagree - strongly agree (7) Don't know

17. The reports recount the facts truthfully.

(1) strongly disagree - strongly agree (7) Don't know

18. The facts that I receive regarding the topic are correct.

(1) strongly disagree - strongly agree (7) Don't know

19. Criticism is expressed in an adequate manner.

(1) strongly disagree - strongly agree (7) Don't know 
20. The journalists' opinions are well-founded.

(1) strongly disagree - strongly agree (7) Don't know

21. The commentary regarding (insert topic) consists of well-reflected conclusions.

(1) strongly disagree - strongly agree (7) Don't know

22. I feel that the journalistic assessments regarding the topic of (insert topic) are useful.

(1) strongly disagree - strongly agree (7) Don't know

Attention Check

10. For this item please check the response option agree.

(1) strongly disagree - strongly agree (7)

Trust measure

23. I trust the content of this news article

(1) strongly disagree - strongly agree (7)

24. What thoughts were going through your mind as you read about this campaign when you were reading this news question? (Free response)

Personal involvement:

Zaichkowsky, J. L. (1994). The personal involvement inventory: Reduction, revision, and application to advertising. Journal of advertising, 23(4), 59-70.

25. Please indicate what the election coverage would mean to you as an individual if you lived in the county referenced by the article you just read by clicking the bubble between each pair (of words and phrases with opposite meanings) that best indicates your reaction:

\section{The election coverage would be}

to me

$\begin{array}{lcccccccl}\text { Important } & 1 & 2 & 3 & 4 & 5 & 6 & 7 & \text { Unimportant } \\ \text { Boring } & 1 & 2 & 3 & 4 & 5 & 6 & 7 & \text { Interesting } \\ \text { Relevant } & 1 & 2 & 3 & 4 & 5 & 6 & 7 & \text { Irrelevant } \\ \text { Exciting } & 1 & 2 & 3 & 4 & 5 & 6 & 7 & \text { Unexciting } \\ \text { Means nothing } & 1 & 2 & 3 & 4 & 5 & 6 & 7 & \text { Means a lot to me } \\ \text { Appealing } & 1 & 2 & 3 & 4 & 5 & 6 & 7 & \text { Unappealing } \\ \text { Fascinating } & 1 & 2 & 3 & 4 & 5 & 6 & 7 & \text { Mundane } \\ \text { Worthless } & 1 & 2 & 3 & 4 & 5 & 6 & 7 & \text { Valuable } \\ \text { Involving } & 1 & 2 & 3 & 4 & 5 & 6 & 7 & \text { Uninvolving } \\ \text { Not needed } & 1 & 2 & 3 & 4 & 5 & 6 & 7 & \text { Needed }\end{array}$




\section{Demographic Questions:}

In the following section, please select the answers that you identify with:

26. Describe your level of interest in national politics

Not interested at all

$$
\begin{array}{lllllll}
1 & 2 & 3 & 4 & 5 & 6 & 7
\end{array}
$$

27. Please specify your political preference

Liberal

$\begin{array}{lllllll}1 & 2 & 3 & 4 & 5 & 6 & 7\end{array}$

Conservative

7

28. Please specify your age:

(drop down panel)

29. Seeking to balance the need for simplicity (and respect people's limited time to answer questions) with a desire, consider the response options:
a. Female
b. Male
c. non-binary/third gender
d. Prefer to self-describe
e. Prefer not to say

30. Please specify your ethnicity.

a. White

b. Hispanic or Latino

c. Black or African American

d. Native American or American Indian

e. Asian/Pacific Islander

f. Other, please specify

31. Please specify your level of education:

a. Some grade school

b. High school diploma or GED

c. College certificate

d. Bachelor's degree

e. Master's degree

f. Doctoral degree

g. Other, please specify

32. What is your current employment status:

a. Employed full time (40+ hour a week) 
b. Employed part time (less than 40 hour a week)

c. Unemployed (currently looking for work)

d. Unemployed (not currently looking for work)

e. Student

f. Retired

g. Self employed

h. Unable to work

33. In which state do you reside?

(drop down panel)

34. What is your annual household income?
a. Below $\$ 10 \mathrm{k}$
b. $\$ 11 \mathrm{k}-\$ 50 \mathrm{k}$
c. $\$ 51 \mathrm{k}-\$ 100 \mathrm{k}$
d. $\$ 101 \mathrm{k}-\$ 150 \mathrm{k}$
e. $\$ 151 \mathrm{k}-\$ 200 \mathrm{k}$
f. $\$ 201 k-\$ 250 k$
g. Over $\$ 251 \mathrm{k}$

\section{Debrief}

This study was designed with the intention of measuring your trust and credibility perceptions that you assign to political news coverage. Prior to answering the questionnaire, you were asked to read an article that was highly interpretive or factually based by design. It is the duty of this research to inform you that the articles utilized in this study are entirely fictional in nature. Thank you for your participation in this study. 


\section{References}

Amazon Mechanical Turk. (2018, December 3). Overview. Retrieved from: https://www.mturk.com

Amazon Mechanical Turk. (2018, December 3). FAQs. Retrieved from: https://www.mturk.com/worker/help

Appelman, A., \& Sundar, S. S. (2016). Measuring Message Credibility. Journalism \& Mass Communication Quarterly, 93(1), 59-79. doi:10.1177/1077699015606057

Barthel, M., \& Gottfried, J. (2016, November 18). Majority of U.S. adults think news media should not add interpretation to the facts. Retrieved March 05, 2018, from http://www.pewresearch.org/fact-tank/2016/11/18/news-media-interpretation-vs-facts/

Barthel, M., \& Mitchell, A. (2017, May 10). Americans' Attitudes About the News Media Deeply Divided Along Partisan Lines. Retrieved from http://www.journalism.org/2017/05/10/americans-attitudes-about-the-news-mediadeeply-divided-along-partisan-lines/

Becker, A. B. (2011). Political Humor as Democratic Relief? The Effects of Exposure to Comedy and Straight News on Trust and Efficacy. Atlantic Journal Of Communication, 19(5), 235250. doi:10.1080/15456870.2011.622191

Binder, S (2014, May 27). Polarized We Govern? Retrieved from https://www.brookings.edu/research/polarized-we-govern/

Bilton, R. (2017, November 30). Why don't people trust the news and social media? A new report lets them explain in their own words. Retrieved from http://www.niemanlab.org/2017/11/why-dont-people-trust-the-news-and-social-media-anew-report-lets-them-explain-in-their-own-words/ 
Budak, C., Goel, S., \& Rao, J. M. (2014). Fair and Balanced? Quantifying Media Bias Through Crowdsourced Content Analysis. SSRN Electronic Journal, 250-271. doi:10.2139/ssrn.2526461

Campbell, A., Converse, P., Miller, W., \& Stokes, D. (1960). The American voter. New York: J. Wiley \& Sons.

Carr, D. J., Barnidge, M., Byung Gu Lee, \& Tsang, S. J. (2014). Cynics and Skeptics: Evaluating the Credibility of Mainstream and Citizen Journalism. Journalism \& Mass Communication Quarterly, 91(3), 452-470. https://doi.org/10.1177/1077699014538828

Carsey, T. M., \& Layman, G. C. (2006). Changing Sides or Changing Minds? Party Identification and Policy Preferences in the American Electorate. American Journal of Political Science, 50(2), 464-477. doi:10.1111/j.1540-5907.2006.00196.x

Chesney, T., \& Su, D. K. (2009). The Impact of Anonymity on Weblog Credibility. SSRN Electronic Journal. doi:10.2139/ssrn.1347651

Coe, K., Tewksbury, D., Bond, B. J., Drogos, K. L., Porter, R. W., Yahn, A., \& Zhang, Y. (2008). Hostile News: Partisan Use and Perceptions of Cable News Programming. Journal of Communication, 58(2), 201-219. https://doi-org.www.libproxy.wvu.edu/10.1111/j.14602466.2008.00381.x

Cole, J. T., \& Greer, J. D. (2013). Audience Response to Brand Journalism: The Effect of Frame, Source, and Involvement. Journalism \& Mass Communication Quarterly, 90(4), 673-690. doi:10.1177/1077699013503160

Curran, J. (2011). Media and democracy. Oxford: Routledge.

Cramer, P., \& Eisenhart, C. (2014). Examining Readers' Evaluations of Objectivity and Bias in News Discourse. Written Communication, 31(3), 280-303.

doi:10.1177/0741088314532429 
Dalton, R. (2016, May 09). Party Identification and Its Implications. Oxford Research Encyclopedia of Politics. Ed. Retrieved 6 Nov. 2018, from http://politics.oxfordre.com/view/10.1093/acrefore/9780190228637.001.0001/acrefore$9780190228637-e-72$.

Dellavigna, S., \& Kaplan, E. (2006). The Fox News Effect: Media Bias and Voting. 1187-1234. doi:10.3386/w12169

Eastlick, M. A., \& Lotz, S. (2011). Cognitive and institutional predictors of initial trust toward an online retailer. International Journal of Retail \& Distribution Management, 39(4), 234255. doi:10.1108/09590551111117527

Eveland, W. P., \& Shah, D. V. (2003). The Impact of Individual and Interpersonal Factors on Perceived News Media Bias. Political Psychology, 24(1), 101-117. doi:10.1111/0162$895 \times .00318$

Esser, F., \& Umbricht, A. (2014). The Evolution of Objective and Interpretative Journalism in the Western Press. Journalism \& Mass Communication Quarterly, 91(2), 229-249. doi:10.1177/1077699014527459

Feldman, L. (2010). Partisan Differences in Opinionated News Perceptions: A Test of the Hostile Media Effect. Political Behavior, 33(3), 407-432. doi:10.1007/s11109-010-9139-4

Fenton, N. (2012). New media, old news: Journalism \& democracy in the digital age. Los Angeles: SAGE.

Fogarty, B. J., \& Wolak, J. (2009). The Effects of Media Interpretation for Citizen Evaluations of Politicians Messages. American Politics Research, 37(1), 129-154. doi:10.1177/1532673x08319953

Gaziano, C., \& Mcgrath, K. (1986). Measuring the Concept of Credibility. Journalism Quarterly, 63(3), 451-462. doi:10.1177/107769908606300301 
Global Trust Index. (n.d.). Retrieved April 15, 2018, from https://www.edelman.com/trust-barometer

Goren, P. (2005). Party Identification and Core Political Values. American Journal of Political Science, 49(4), 881. doi:10.2307/3647703

Greene, S. (1999). Understanding Party Identification: A Social Identity Approach. Political Psychology, 20(2), 393-403. doi:10.1111/0162-895x.00150

Guggenheim, L., Kwak, N., \& Campbell, S. W. (2011). Nontraditional News Negativity: The Relationship of Entertaining Political News Use to Political Cynicism and Mistrust. International Journal of Public Opinion Research, 23(3), 287-314. doi:10.1093/ijpor/edr015

Gunther, A. C. (1992). Biased Press or Biased Public? Attitudes Toward Media Coverage of Social Groups. Public Opinion Quarterly, 56(2), 147-167. doi:10.1086/269308

Hanitzsch, T., Van Dalen, A., \& Steindl, N. (2018). Caught in the Nexus: A Comparative and Longitudinal Analysis of Public Trust in the Press. International Journal Of Press/Politics, 23(1), 3-23. doi:10.1177/1940161217740695

Heath, C. (1996). Do People Prefer to Pass Along Good or Bad News? Valence and Relevance of News as Predictors of Transmission Propensity. Organizational Behavior and Human Decision Processes, 68(2), 79-94. doi:10.1006/obhd.1996.0091

Hetherington, M. J. (2005). Why trust matters: Declining political trust and the demise of American liberalism. Princeton, NJ: Princeton University Press.

Hoffman, L. H., \& Young, D. G. (2011). Satire, Punch Lines, and the Nightly News: Untangling Media Effects on Political Participation. Communication Research Reports, 28(2), 159168. doi:10.1080/08824096.2011.565278 
Hopmann, D. N., Shehata, A., \& Strömbäck, J. (2015). Contagious Media Effects: How Media Use and Exposure to Game-Framed News Influence Media Trust. Mass Communication \& Society, 18(6), 776-798. doi:10.1080/15205436.2015.1022190

Jefferson, T. (1786, January 28). From Thomas Jefferson to James Currie, 28, January 1786 [Letter to James Currie].

Johnson, T. J., Kaye, B. K., Bichard, S. L., \& Wong, W. J. (2007). Every Blog Has Its Day: Politically-interested Internet Users' Perceptions of Blog Credibility. Journal of ComputerMediated Communication, 13(1), 100-122. doi:10.1111/j.1083-6101.2007.00388.x

Johnson, T. J., \& Kaye, B. K. (2009). In blog we trust? Deciphering credibility of components of the internet among politically interested internet users. Computers in Human Behavior, 25(1), 175-182.

Jones, D. A. (2004). Why Americans Don't Trust the Media. Harvard International Journal Of Press/Politics, 9(2), 60-75. doi:10.1177/1091191X04263461

Jones, K. (2005). Trust as an Affective Attitude. Personal Virtues, 253-279. doi:10.1007/978-0-230-20409-6_11

Journalists Resource. (n.d.). Share of news reports about the Trump administration with a positive or negative tone from January to April 2017, by news outlet. In Statista - The Statistics Portal. Retrieved November 2, 2018, from https://www.statista.com/statistics/800579/trump-news-tone-outlet/.

Jost, J. T., Nosek, B. A., \& Gosling, S. D. (2008). Ideology: Its Resurgence in Social, Personality, and Political Psychology. Perspectives on Psychological Science, 3(2), 126136. doi:10.1111/j.1745-6916.2008.00070.x

Juffinger, A., Granitzer, M., \& Lex, E. (2009). Blog credibility ranking by exploiting verified content. Proceedings of the 3rd Workshop on Information Credibility on the Web WICOW 09. doi:10.1145/1526993.1527005 
Kang, M. (2010). Measuring social media credibility: A study on a measure of blog credibility. Institute for Public Relations. Retrieved from: http://www.instituteforpr.org/wpcontent/uploads/BlogCredibility101210.pdf

Karlsson, M., Clerwall, C., \& Nord, L. (2014). You Ain't Seen Nothing Yet: Transparency's (lack of) effect on source and message credibility. Journalism Studies, 15(5), 668-678.

Kim, K. S., \& Pasadeos, Y. (2007). Study of Partisan News Readers Reveals Hostile Media Perceptions of Balanced Stories. Newspaper Research Journal, 28(2), 99-106. doi:10.1177/073953290702800207

Kiousis, S. (2006). Exploring the Impact of Modality on Perceptions of Credibility for Online News Stories. Journalism Studies, 7(2), 348-359. https://doiorg.www.libproxy.wvu.edu/10.1080/14616700500533668

Kock, N., \& Lynn, G. (2012). Lateral Collinearity and Misleading Results in Variance-Based SEM: An Illustration and Recommendations. Journal of the Association for Information Systems, 13(7), 546-580. doi:10.17705/1jais.00302

Kohring, M., \& Matthes, J. (2007). Trust in News Media. Communication Research, 34(2), 231-252. doi:10.1177/0093650206298071

Kovach, Bill, and Tom Rosenstiel. 2001. The Elements of Journalism: What Newspeople Should Know and the Public Should Expect. New York: Random House.

Ladd, J. (2010). The Role of Media Distrust in Partisan Voting. Political Behavior, 32(4), 567-585. doi:10.1007/s11109-010-9123-z

LaLoggia, J. (2018, August 23). Republicans, Democrats agree: They can't agree on basic facts. Retrieved from http://www.pewresearch.org/fact-tank/2018/08/23/republicans-anddemocrats-agree-they-cant-agree-on-basic-facts/

Lawrence, R. G. (2000). Game-Framing the Issues: Tracking the Strategy Frame in Public Policy News. Political Communication, 17(2), 93-114. doi:10.1080/105846000198422 
Lee, T. (2010). Why They Don't Trust the Media: An Examination of Factors Predicting Trust. American Behavioral Scientist, 54(1), 8-21. doi:10.1177/0002764210376308

Lin, M., Haridakis, P. M., \& Hanson, G. (2016). The Role of Political Identity and Media Selection on Perceptions of Hostile Media Bias During the 2012 Presidential Campaign. Journal Of Broadcasting \& Electronic Media, 60(3), 425-447. doi:10.1080/08838151.2016.1203316

Luberda, R. (2014). The Fourth Branch of the Government: Evaluating the Media's Role in Overseeing the Independent Judiciary. Notre Dame Journal of Law, Ethics \& Public Policy, 22(2), 507-532.

Mayer, R. C., Davis, J. H., \& Schoorman, F. D. (1995). An Integrative Model of Organizational Trust. Academy of Management Review, 20(3), 709-734. Retrieved from https://www.jstor.org/stable/258792?seq=1\#metadata_info_tab_contents.

McComas, K. A., \& Trumbo, C. W. (2001). Source Credibility in Environmental Health - Risk Controversies: Application of Meyer's Credibility Index. Risk Analysis: An International Journal, 21(3), 467-480. Retrieved from http://search.ebscohost.com/login.aspx?direct=true\&db=buh\&AN=6632617\&site=ehostlive

McKnight, D. H., \& Kacmar, C. J. (2007). Factors and effects of information credibility. Proceedings of the Ninth International Conference on Electronic Commerce - ICEC 07. doi:10.1145/1282100.1282180

Metzger, M. J., Hartsell, E. H., \& Flanagin, A. J. (2015). Cognitive Dissonance or Credibility? Communication Research, 009365021561313. doi:10.1177/0093650215613136 
Mitchell, A., Gottfried, J., Stocking, G., Matsa, K. E., \& Grieco, E. (2017, October 02). Five topics accounted for two-thirds of news coverage in Trump's first 100 days. Retrieved from http://www.journalism.org/2017/10/02/five-topics-accounted-for-two-thirds-ofcoverage-in-first-100-days/\#

Morris, J. S. (2007). Slanted Objectivity? Perceived Media Bias, Cable News Exposure, and Political Attitudes. Social Science Quarterly, 88(3), 707-728. doi:10.1111/j.15406237.2007.00479.x

Mothes, C. (2017). Biased Objectivity: An Experiment on Information Preferences of Journalists and Citizens. Journalism \& Mass Communication Quarterly, 94(4), 1073-1095. https://doi.org/10.1177/1077699016669106

Müller, J. (2013). Mechanisms of trust: News media in democratic and authoritarian regimes. Frankfurt: Campus.

Muñoz-Torres, J. R. (2012). Truth and Objectivity in Journalism. Journalism Studies, 13(4), 566-582. https://doi.org/10.1080/1461670X.2012.662401

Mutz, D. (1995). Effects of Horse-Race Coverage on Campaign Coffers: Strategic Contributing in Presidential Primaries. The Journal of Politics, 57(4), pp.1015-1042.

Nelson, B. (2012, July 30). Do You Read Fast Enough To Be Successful? Retrieved from https://www.forbes.com/sites/brettnelson/2012/06/04/do-you-read-fast-enough-to-besuccessful/\#9faa129462e7

Patterson, T. E. (1993). Out of order. New York: Knopf

Patterson, T. E. (1996). Bad News, Bad Governance. The ANNALS of the American Academy of Political and Social Science, 546(1), 97-108. https://doi.org/10.1177/0002716296546001009 
Patterson, T. (2017, June 13). News Coverage of the 2016 General Election: How the Press Failed the Voters. Retrieved November 13, 2017, from https://shorensteincenter.org/news-coverage-2016-general-election/

Praveen Kumar, N. (2016). Journalistic objectivity in Media risk debates: challenges \& opportunities. Clarion: International Multidisciplinary Journal, 5(1), 91-97. https://doi.org/10.5958/2277-937X.2016.00013.7

Pressgrove, G., \& Kim, C. (2018). Stewardship, credibility and political communications: A content analysis of the 2016 election. Public Relations Review, 44(2), 247-255. doi:10.1016/j.pubrev.2018.01.003

Renn, O., \& Levine, D. (1991). Credibility and trust in risk communication. In Communicating risks to the public (pp. 175-217). Springer, Dordrecht.

Rousseau, D. M., S. B. Sitkin, R. S. Burt, and C. Camerer. 1998. "Not So Different After All: A Cross-Discipline View of Trust." Academy of Management Review 23:393-404.

Salgado, S., \& Strömbäck, J. (2011). Interpretive journalism: A review of concepts, operationalizations and key findings. Journalism: Theory, Practice \& Criticism, 13(2), 144-161. doi:10.1177/1464884911427797

Shen, F., Ahern, L., \& Backer, M. (2014). Stories that Count: Influence of News Narratives on Issue Attitudes. Journalism \& Mass Communication Quarterly, 91(1), 98-117. doi:10.1177/1077699013514414

Singletary, M. W. (1976). Components of Credibility of a Favorable News Source. Journalism Quarterly, 53(2), 316-319. doi:10.1177/107769907605300219

Slater, M. D., \& Rouner, D. (1996). How Message Evaluation and Source Attributes May Influence Credibility Assessment and Belief Change. Journalism \& Mass Communication Quarterly, 73(4), 974-991. doi:10.1177/107769909607300415 
Smith, S. (2016, April 13). A Deep Dive Into Party Affiliation | Pew Research Center. Retrieved from http://www.people-press.org/2015/04/07/a-deep-dive-into-party-affiliation/

Soroka, S., \& McAdams, S. (2015). News, Politics, and Negativity. Political Communication, 32(1), 22nd ser., 1-22. doi:10.1080/10584609.2014.881942

SPJ Code of Ethics - Society of Professional Journalists. (n.d.). Retrieved from https://www.spj.org/ethicscode.asp

Stanford University. (n.d.). Democracy Education for Iraq-Nine Brief Themes. Retrieved June 26, 2018, from https://web.stanford.edu/ Idiamond/iraq/DemocracyEducation0204.htm

Stroud, N. J., \& Lee, J. K. (2013). Perceptions of Cable News Credibility. Mass Communication \& Society, 16(1), 67-88. doi:10.1080/15205436.2011.646449

Sundar, S. S. (1998). Effect of Source Attribution on Perception of Online News Stories. Journalism \& Mass Communication Quarterly, 75(1), 55-68. doi:10.1177/107769909807500108

Sundar, S. S. (1999). Exploring receivers' criteria for perception of print and online news. Journalism \& Mass Communication Quarterly, 76, 373-386. doi:10.1177/ 107769909907600213

Swift, A. (2016, September 14). Americans' Trust in Mass Media Sinks to New Low. Retrieved March 05, 2018, from http://news.gallup.com/poll/195542/americans-trust-mass-mediasinks-new-low.aspx

Tsfati, Y., \& Ariely, G. (2013). Individual and Contextual Correlates of Trust in Media Across 44 Countries. Communication Research, 41(6), 760-782. doi:10.1177/0093650213485972 
Van Reijmersdal, E. A., Neijens, P. C., \& Smit, E. G. (2010). Customer Magazines: Effects of Commerciality on Readers' Reactions. Journal of Current Issues \& Research in Advertising (CTC Press), 32(1), 59-67. Retrieved from http://www.libproxy.wvu.edu/login?url=http://search.ebscohost.com/login.aspx?direct=tru $e \& d b=b u h \& A N=51923975$

Wathen, C. N., \& Burkell, J. (2002). Believe it or not: Factors influencing credibility on the Web. Journal of the American Society for Information Science and Technology, 53(2), 134144. doi:10.1002/asi.10016

Whitehead, J. L., Jr. (1968). Factors of source credibility. Quarterly Journal of Speech, 54(1), 59-63. doi:10.1080/00335636809382870

Whitten-Woodring, J. (2009). Watchdog or Lapdog? Media Freedom, Regime Type, and Government Respect for Human Rights. International Studies Quarterly, 53(3), 595-625. doi:10.1111/j.1468-2478.2009.00548.x

Zaichkowsky, J. L. (1994). The personal involvement inventory: Reduction, revision, and application to advertising. Journal of advertising, 23(4), 59-70.

Zanna, M. P., \& Del Vecchio, S. M. (1973). Perceived credibility of television news: A matter of viewer's attitudes and the position taken by the media. European Journal of Social Psychology, 3(2), 213-216. https://doi.org/10.1002/ejsp.2420030210

Zúñiga, H. G., Jung, N., \& Valenzuela, S. (2012). Social Media Use for News and Individuals Social Capital, Civic Engagement and Political Participation. Journal of ComputerMediated Communication, 17(3), 319-336. doi:10.1111/j.1083-6101.2012.01574.x 